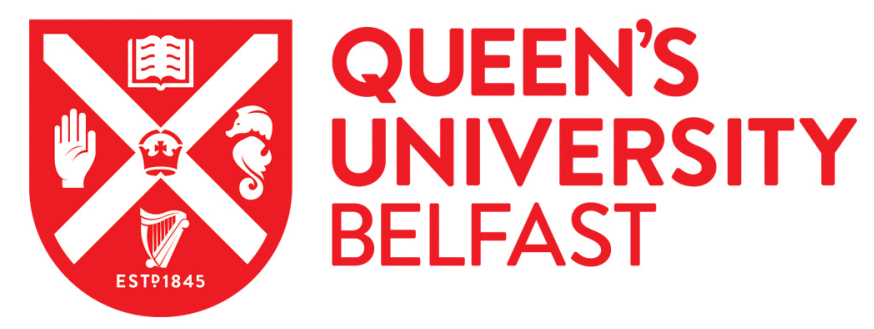

\title{
Correlation of the ratio of metallic to oxide species with activity of PdPt catalysts for methane oxidation
}

Nguyen, T. S., McKeever, P., Arredondo-Arechavala, M., Wang, Y-C., Slater, T. J. A., Haigh, S. J., Beale, A. M., \& Thompson, J. M. (2020). Correlation of the ratio of metallic to oxide species with activity of PdPt catalysts for methane oxidation. Catalysis, Science \& technology, 10(5), 1408-1421. https://doi.org/10.1039/c9cy02371b

Published in:

Catalysis, Science \& technology

Document Version:

Peer reviewed version

Queen's University Belfast - Research Portal:

Link to publication record in Queen's University Belfast Research Portal

Publisher rights

Copyright 2020 Royal Society of Chemistry. This work is made available online in accordance with the publisher's policies. Please refer to any applicable terms of use of the publisher.

\section{General rights}

Copyright for the publications made accessible via the Queen's University Belfast Research Portal is retained by the author(s) and / or other copyright owners and it is a condition of accessing these publications that users recognise and abide by the legal requirements associated with these rights.

\section{Take down policy}

The Research Portal is Queen's institutional repository that provides access to Queen's research output. Every effort has been made to ensure that content in the Research Portal does not infringe any person's rights, or applicable UK laws. If you discover content in the Research Portal that you believe breaches copyright or violates any law, please contact openaccess@qub.ac.uk. 


\section{Correlation of the ratio of metallic to oxide species with activity of PdPt catalysts for methane oxidation}

Received 00th January 20xx, Accepted 00th January 20xx

DOI: $10.1039 / x 0 x \times 00000 x$
Tang Son Nguyen ${ }^{a, b *}$, Paul McKeevera, Miryam Arredondo-Arechavalac, Yi-Chi Wang ${ }^{d}$, Thomas J. A. Slater ${ }^{\mathrm{e}}$, Sarah J. Haigh ${ }^{\mathrm{d}}$, Andrew M. Beale ${ }^{\mathrm{f} *}$, Jillian M. Thompson ${ }^{\mathrm{a} *}$

Bimetallic catalysts consisting of $\mathrm{Pd}$ and $\mathrm{Pt}$ on $\mathrm{TiO}_{2}$-zeolite (mordenite, beta, $\mathrm{ZSM}-5$ ) supports were prepared and tested for the combustion of methane. The activity of the catalysts was found to be dependent on the zeolite topology and $\mathrm{SiO}_{2}: \mathrm{Al}_{2} \mathrm{O}_{3}$ ratio and was linearly dependent on the proportion of Pd and Pt present in a bimetallic phase observed in XRD diffractograms of the catalysts. This linear dependence was valid for a range of zeolites used. STEM-EDS and electron tomography showed the Pd and Pt to be largely co-located and XAS and XPS indicated that the metals are mostly present in the form of oxide nanoparticles with a minor contribution from the metals at high $\mathrm{SiO}_{2}: \mathrm{Al}_{2} \mathrm{O}_{3}$ ratios. Catalyst characterization showed there to be little difference overall in the metal loading and physical characteristics of the samples and $\mathrm{NH}_{3}$-TPD suggested that the activation of methane over acid sites is not important. Adding water to the feed, slightly reduced the conversion but did not affect the deactivation profile of the catalysts tested.

\section{Introduction}

Natural gas has gained popularity in transport, power generation and heating applications due to its abundance, versatility and high calorific value. Methane is available from a number of sources including oil reserves, as shale gas and is generated from renewable sources by digestion of biomass. However it has a greenhouse gas potential 20 to 100 times higher than that of $\mathrm{CO}_{2}{ }^{1}$. Thus, incomplete combustion is not only a waste of resource but also causes severe environmental issues. Although methane should burn to give only $\mathrm{CO}_{2}$ and $\mathrm{H}_{2} \mathrm{O}$, due to its highly symmetrical structure, and consequently high stability, activation of the combustion reaction requires either high temperature or the presence of a catalyst. In thermal combustion, the high temperature results in the formation of various pollutants including $\mathrm{NO}_{x}, \mathrm{CO}$ as well as an unburned portion. ${ }^{2}$ Catalytic combustion of methane operating at lower temperatures not only requires less energy input but also reduces the emission of pollutants making it an efficient and

a. School of Chemistry and Chemical Engineering, Queen's University Belfast, Belfast BT9 5AG, Northern Ireland, UK

b. Faculty of Biotechnology, Chemistry and Environmental Engineering, PHENIKAA University, Hanoi 10000, Vietnam

c. Centre for Nanostructured Media, School of Mathematics and Physics, Queen's University Belfast, University Road, Belfast BT7 1NN, UK

d. School of Materials, University of Manchester, Oxford Road, Manchester

M13 9PL, UK

e. Electron Physical Sciences Imaging Centre, Diamond Light Source Ltd., Oxfordshire OX11 ODE, UK

f. Department of Chemistry, University College London, 20 Gordon Street, London WC1H OAJ, U.K., \& Research Complex at Harwell, Rutherford Appleton Laboratory, Didcot OX11 OFA, UK

Electronic Supplementary Information (ESI) available: [BET plot; $\mathrm{NH}_{3}$-TPD profiles; SEM images; STEM-HAADF reconstructions; EXAFS fitting and parameters; XPS peak positions; characterisation of fresh and aged catalysts; activity and stability tests with water in the feed stream]. See DOI: 10.1039/x0xx00000x less environmentally damaging strategy for methane utilization. ${ }^{3,4}$ Low temperature catalytic methane combustion has received increased interest specifically in the area of after treatment for emissions from natural gas-powered vehicles. ${ }^{5,6}$ Increasingly stringent European legislation requiring separate monitoring of methane and non-methane hydrocarbons from vehicles means that many natural gas and dual fuel powered vehicles no longer meet these requirements. Development of a catalyst to allow abatement of these emissions is vital for the utilisation of methane in transportation in the future. ${ }^{7}$

It is widely agreed that Pd-based materials are the most active catalysts for methane combustion ${ }^{3}$, with a number of studies using $\mathrm{Pd}$-based catalysts showing considerable activity below $300{ }^{\circ} \mathrm{C}^{8-10}$. The mechanism by which methane combustion occurs over Pd catalysts has been proposed to proceed via the dissociative adsorption of methane on metallic Pd to form methyl surface species, which are subsequently oxidised into the final products by the presence of PdO. ${ }^{11,12}$ Thus, an intricate balance between the metallic and oxide forms of Pd on the surface appears to be a requisite for high activity and stability. Zeolites are often employed as a support for methane combustion catalysts and besides their role as a dispersion media, the surface acidity of zeolites has also been shown to influence the catalytic activity. ${ }^{13-16}$ It was proposed that the $\mathrm{C}-\mathrm{H}$ bond in short-chain alkanes could be activated via protolysis at low temperatures over the Brønsted acid sites of zeolite. ${ }^{17}$ However, Dai et al. comprehensively studied the role of different acid sites in the catalytic combustion of methane over $\mathrm{PdO} / \mathrm{H}-\mathrm{ZSM}-5$ catalysts and it was confirmed that the role of Brønsted acid sites on the direct activation of methane was negligible. ${ }^{18}$ In the same study, the dispersion of $\mathrm{PdO}$ was shown to be dependent on acid sites of supports and the influence of Lewis acid sites in particular was considered more decisive (i.e. 
through dispersion and stabilization of $\left.\mathrm{PdO}_{\mathrm{x}}\right)^{18}$. Okumura et al. further confirmed the role of the acid sites in H-ZSM-5 in controlling the dispersion and thus the activity of palladium in methane combustion ${ }^{16}$. It was proposed that PdO species were anchored on the acid sites of the zeolite support through acidbase interactions, consequently leading to higher stability and smaller Pd particles being achieved with H-ZSM-5 supports of lower $\mathrm{SiO}_{2}: \mathrm{Al}_{2} \mathrm{O}_{3}$ ratios. One of the key findings of this study was the dependence of catalytic activity on the $\mathrm{SiO}_{2}: \mathrm{Al}_{2} \mathrm{O}_{3}$ ratio of the H-ZSM-5 support, which spans from 24 to 1000 . The activity was shown to increase with the $\mathrm{SiO}_{2}: \mathrm{Al}_{2} \mathrm{O}_{3}$ ratio, reaching a maximum at a value of 200 before decreasing. Interestingly, these results suggest that initially the activity of the $\mathrm{PdO} / \mathrm{H}$ ZSM-5 catalyst is inversely proportional to $\mathrm{PdO}$ dispersion up to a $\mathrm{SiO}_{2}: \mathrm{Al}_{2} \mathrm{O}_{3}$ ratio of 200 . The authors finally concluded that the activity of Pd for methane combustion followed the order: PdO dispersed $<\mathrm{PdO}$ agglomerated $<$ mixture of Pd metal and $\mathrm{PdO}^{16}$. Lou et al. employed different experimental techniques in combination with DFT calculations to study the active site in low-temperature methane combustion over a $\mathrm{Pd} / \mathrm{H}-\mathrm{ZSM}-5$ catalyst ${ }^{10}$. It was shown that $\left[\mathrm{AlO}_{2}\right] \mathrm{Pd}(\mathrm{OH})-\mathrm{ZSM}-5$ sites, formed by the interaction between $\mathrm{PdO}_{x}$ and the surface Brønsted acid sites of $\mathrm{H}-\mathrm{ZSM}-5$ are likely the active species in the catalyst. Furthermore, the catalytic activity increases with an increase in the $\mathrm{Pd}^{\mathrm{n}+} / \mathrm{Pd}^{2+}$ ratio $(0<\mathrm{n}<2)$, suggesting that $\mathrm{Pd}$ species with lower oxidation states will benefit the activity for methane combustion $^{10}$.

Osman et al. reported the utilization of $\mathrm{H}-\mathrm{ZSM}-5$ and $\mathrm{TiO}_{2}$ as a dual component support for a bimetallic Pd-Pt catalyst which resulted in a methane combustion catalyst with activity below $250{ }^{\circ} \mathrm{C} .{ }^{19}$ It was noted that the presence of Pt enhanced the activity and stability of the catalyst. The use of $\mathrm{TiO}_{2}$ on the support, was reported to assist in the transport of oxygen for the oxidation of $\mathrm{Pd}$ and also in facilitating the reduction of $\mathrm{PdO}$ to Pd metal and thus maintaining sufficient sites for dissociative methane adsorption. The importance of sonication in the catalyst synthesis was attributed to ensuring thorough mixing of catalyst components, required for high activity, however, the distribution of the metals on the $\mathrm{TiO}_{2}$ and zeolite was not clear. The acidity of $\mathrm{H}-\mathrm{ZSM}-5$ was also shown to influence the activity of the bimetallic catalysts, however, this was not systematically studied. The observation of an optimum $\mathrm{TiO}_{2}$ loading and zeolite acidity highlights the fine balance of catalyst components required for optimised activity; an improved understanding of the role of the support acidity and the distribution of catalyst components provides the motivation for the current study.

In this current work, catalysts comprising of $\mathrm{Pd}, \mathrm{Pt}$ and $\mathrm{TiO}_{2}$ with zeolite supports of different topologies and $\mathrm{H}-\mathrm{ZSM}-5$ supports of different $\mathrm{SiO}_{2}: \mathrm{Al}_{2} \mathrm{O}_{3}$ ratios were synthesized using the composition optimised previously. ${ }^{19} \mathrm{~A}$ comprehensive range of characterization techniques were employed to further understand the interaction and distribution of catalyst components as well as the influence of the acidity of the support on the catalytic activity in the methane combustion reaction.

\section{Experimental}

\subsection{Materials}

The materials used to prepare and characterise the catalysts as well as test their activity were analytical grade and were used as received. Palladium (II) nitrate dihydrate $\left(\mathrm{Pd}\left(\mathrm{NO}_{3}\right)_{2} \cdot 2 \mathrm{H}_{2} \mathrm{O}\right.$, $\sim 40 \%$ Pd basis) and titanium (IV) oxide anatase nanopowder $\left(\mathrm{TiO}_{2}, 99.7 \%\right.$ anatase) were obtained from Sigma-Aldrich. Tetraammine platinum (II) hydroxide in solution $\left(\mathrm{Pt}\left(\mathrm{NH}_{3}\right)_{4}(\mathrm{OH})_{2}\right.$, assay $9.09 \%$ ) was obtained from Alfa Aesar as were the samples of the MFI framework zeolite $\mathrm{ZSM}-5\left(\mathrm{SiO}_{2}: \mathrm{Al}_{2} \mathrm{O}_{3}\right.$ 23:1, 30:1, 50:1 and $80: 1$ molar ratio), mordenite $\left(\mathrm{SiO}_{2}: \mathrm{Al}_{2} \mathrm{O}_{3}\right.$ of $\left.20: 1\right)$, and beta $\left(\mathrm{SiO}_{2}: \mathrm{Al}_{2} \mathrm{O}_{3}\right.$ of 38:1). All gases ( $\mathrm{Ar}, 20 \% \mathrm{O}_{2} / \mathrm{Ar}, \mathrm{CH}_{4}, \mathrm{NH}_{3} / \mathrm{Ar}, \mathrm{N}_{2}$, $\mathrm{Ne}$ ) were obtained from $\mathrm{BOC}$ and had $100 \%$ purity.

\subsection{Preparation of Palladium/Platinum catalysts.}

The catalysts were prepared using wet impregnation. Typically, zeolite $(1.51 \mathrm{~g})$ was placed in a beaker with an appropriate amount of precursor to result in a catalyst with $5 \mathrm{wt} . \% \mathrm{Pd}, 2$ wt.\% Pt and 17.5 wt.\% $\mathrm{TiO}_{2}$. Deionised water $(\sim 5 \mathrm{~mL})$ was added to the beaker which was placed in an ultrasonic bath (Crest 200 $\mathrm{HT}$ ) and sonicated at $80{ }^{\circ} \mathrm{C}$ using a frequency of $45 \mathrm{kHz}$ for 3 hours. All mixtures were then evaporated to dryness in an oven at $110{ }^{\circ} \mathrm{C}$ overnight and calcined in air at $550{ }^{\circ} \mathrm{C}$ for $4 \mathrm{~h}$ with a heating ramp of $1{ }^{\circ} \mathrm{C} \mathrm{min}-1$. Herein the catalysts are referred to as $\mathrm{Pd}, \mathrm{Pt}, \mathrm{TiO}_{2}$ /zeolite according to the zeolite support, which includes $\mathrm{H}-\mathrm{ZSM}-5, \mathrm{H}-\mathrm{MOR}$ and $\mathrm{H}-\mathrm{BEA}$ with their $\mathrm{SiO}_{2}: \mathrm{Al}_{2} \mathrm{O}_{3}$ ratio given in brackets e.g. the catalyst sample with $\mathrm{Pd}$ and $\mathrm{Pt}$ on the $\mathrm{H}-\mathrm{ZSM}-5$ zeolite support with a $\mathrm{SiO}_{2}: \mathrm{Al}_{2} \mathrm{O}_{3}$ ratio of $23: 1$, is referred to as $\mathrm{Pd}, \mathrm{Pt}, \mathrm{TiO}_{2} / \mathrm{H}-\mathrm{ZSM}-5$ (23). The weight percentages are assumed to be $5 \mathrm{wt} . \% \mathrm{Pd}, 2 \mathrm{wt} . \% \mathrm{Pt}$ and $17.5 \mathrm{wt} . \% \mathrm{TiO}_{2}$ unless otherwise stated.

After drying the catalyst at $110{ }^{\circ} \mathrm{C}$ but not calcining in air, a sample was pre-reduced by heating in $\mathrm{H}_{2}$ to $100{ }^{\circ} \mathrm{C}$. This temperature is lower than that required for the reduction of $\mathrm{TiO}_{2}$ but higher than that required for the reduction of $\mathrm{PdO}$. This catalyst was then heated in $\mathrm{Ar}$ to $550^{\circ} \mathrm{C}$ before cooling to room temperature and then calcined at $550^{\circ} \mathrm{C}$ as described above.

\subsection{Catalyst Characterization}

Surface areas and pore volumes of the supports and catalysts were obtained using Brunauer-Emmett-Teller (BET) analysis which included criteria proposed by Rouquerol et al. ${ }^{20}$ (ESI 1). The data, measured by the $\mathrm{N}_{2}$ adsorption and desorption isotherm at $-196{ }^{\circ} \mathrm{C}$, at relative pressures below 0.1 were obtained on a Micromeritics TriStar II 3020 system.

ICP analysis was carried out using an Agilent Technologies 5100 ICP-OES system, with the samples being prepared by sodium peroxide fusion and dissolution in acid before analysis.

Powder X-ray diffractograms (XRD) were obtained on a PANalytical $X^{\prime}$ Pert Pro $X$-ray diffractometer, equipped with a $\mathrm{Cu}$ $\mathrm{K}_{\alpha} \mathrm{X}$-ray source of wavelength $1.5406 \AA$. The $\mathrm{X}$-ray tube was set at $40 \mathrm{kV}$ and $40 \mathrm{~mA}$ and data collected between 5 and $80^{\circ} 2 \theta$. Peaks were identified by comparison with diffraction patterns in the software library as well as with zeolite standard samples. The PdO crystallite size was calculated from the reflection (101) 
at $34.6^{\circ} 2 \theta$ using the Scherrer Equation, in which the peak width at half maximum intensity was calculated by the peak fitting function in the programme Highscore Plus.

Ammonia temperature-programmed desorption ( $\mathrm{NH}_{3}-\mathrm{TPD}$ ) and temperature-programmed reduction (TPR) data were obtained on a Micromeritics Autochem II apparatus with the $\mathrm{H}_{2}$ uptake monitored by a thermal conductivity detector (TCD). Typically for $\mathrm{NH}_{3}$-TPD, a sample of catalyst $(0.1 \mathrm{~g})$ was degassed at $550{ }^{\circ} \mathrm{C}$ under a $50 \mathrm{~mL} \mathrm{~min}^{-1}$ flow of Ar for $1 \mathrm{~h}$ (with a heating rate of $5{ }^{\circ} \mathrm{C} \mathrm{min}^{-1}$ ) then; the sample was cooled to $100^{\circ} \mathrm{C}$ and saturated with a $50 \mathrm{~mL} \mathrm{~min}^{-1}$ flow of $2 \% \mathrm{NH}_{3} / \mathrm{Ar}$ for $0.5 \mathrm{~h}$. The sample was then purged with argon, at $100 \mathrm{~mL} \mathrm{~min}^{-1}$ for $45 \mathrm{~min}$, to remove weakly and physically adsorbed $\mathrm{NH}_{3}$ on the surface of the catalyst. Finally, the sample was heated at a rate of $5{ }^{\circ} \mathrm{C} \mathrm{min}-1$ under a $50 \mathrm{~mL} \mathrm{~min}-1$ flow of $\mathrm{Ar}$ from $100{ }^{\circ} \mathrm{C}$ to $600{ }^{\circ} \mathrm{C}$ and the amount of $\mathrm{NH}_{3}$ in the effluent was measured via the TCD. For the TPR analysis, Ar was flowed over the sample until the temperature was decreased to $50^{\circ} \mathrm{C} .5 \% \mathrm{H}_{2} / \mathrm{Ar}$ was then passed over the catalyst at $30 \mathrm{~mL} \mathrm{~min}{ }^{-1}$ until a stable baseline was obtained when the sample was heated at $10{ }^{\circ} \mathrm{C} \mathrm{min}-1$ up to $600{ }^{\circ} \mathrm{C}$.

Transmission electron microscope (TEM) characterisation was performed using a Thermo Fisher Talos F200X G2 fitted with the Super-X energy dispersive X-ray spectrometer (EDS) detector configuration having a total collection angle of $\sim 0.9 \mathrm{sr}$ and operated at $200 \mathrm{kV}$ using high angle annular dark field (HAADF) scanning TEM (STEM) and EDS. The Si-K, Al-K, Ti-K, Pt-L and Pd$L$ peaks were used to generate the EDS elemental maps. The samples did not undergo any pre-treatment before analysis. High resolution STEM-HAADF images shown in Figure 6 were acquired using a probe-corrected Thermo Fisher Titan G2 80 $200 \mathrm{~S} / \mathrm{TEM}$ operated at $200 \mathrm{kV}$, and equipped with an X-FEG high brightness source and STEM probe aberration corrector.

STEM-HAADF tomography acquisition was performed with a Fischione 2020 tomography holder in the same Thermo Fisher Talos STEM instrument. The accelerating voltage was $200 \mathrm{kV}$, probe current $\sim 80 \mathrm{pA}$, EDS pixel dwell time $40 \mu$ s with total scan frames for spectrum images of 100 frames (frame size $512 x$ 512). For low magnification tomography, the tilting range was from $+78^{\circ}$ to $-72^{\circ}$ with $2^{\circ}$ increments and a pixel size of $0.47 \mathrm{~nm}$. Pixel sizes were binned to $0.94 \mathrm{~nm}$ for reconstruction. For high magnification tomography, the tilting range was from $-76^{\circ}$ to $74^{\circ}$ with $2^{\circ}$ increments and a pixel size of $0.11 \mathrm{~nm}$. Dwell time is $10 \mu \mathrm{s}$. In the Tomviz reconstruction software ${ }^{21}$, images and tilt axes were aligned automatically and image intensities were normalised before using the Total Variation Minimization (TVM) reconstruction method ${ }^{22}$ applied with 10 iterations.

$\mathrm{X}$-ray absorption fine structure (XAFS) studies were performed at the B18 beamline at the Diamond Light Source in Harwell, United Kingdom. The X-ray energy was $3 \mathrm{GeV}$ and the ring current $300 \mathrm{~mA}$. Pd K and Pt $\mathrm{L}_{\| 1}$-edges were recorded in transmission mode using ion chamber detectors with a fast scanning Si (1 111$)$ double crystal monochromator. The acquisition of each spectra took $\sim 60 \mathrm{~s}$, with the respective metal foils placed between $\mathrm{I}_{\mathrm{t}}$ and $\mathrm{I}_{\text {ref. }}$. The dimension of the $\mathrm{X}$ ray beam used was $1 \times 1 \mathrm{~mm}^{2}$. X-ray absorption spectroscopy
(XAS) data analysis was performed using the Demeter software package. ${ }^{23}$

X-ray photoelectron spectroscopy (XPS) was performed on a Kratos AXIS Supra spectrophotometer, equipped with a monochromatic Al $\mathrm{K}_{\alpha}$ source $(1486.7 \mathrm{eV})$ and a charge neutraliser. Spectra were processed with CasaXPS software version 2.3.16 and Origin software version 8.6 and quantified after Shirley background correction and application of relevant response factors to quantification regions.

\subsection{Catalyst activity}

The activity of the catalysts for methane oxidation was tested in a stainless steel fixed-bed reactor ( $1 / 4$ " outer diameter) at atmospheric pressure. The catalyst $(0.108 \mathrm{~g})$, was sieved to between 250 and $425 \mu \mathrm{m}$ and was placed centrally in the reactor between two plugs of quartz wool with an Omega thermocouple placed in the centre of the bed to monitor the reaction temperature. The flow of $\mathrm{Ar}, \mathrm{O}_{2} / \mathrm{Ar}$ and $\mathrm{Ne}$ to the reactor was controlled using Aalborg mass flow controllers, whilst that of $\mathrm{CH}_{4}$ was controlled by a Bronkhorst mass flow controller. The catalyst was heated at a rate of $5^{\circ} \mathrm{C} \mathrm{min}^{-1}$ to 500 ${ }^{\circ} \mathrm{C}$ for $2 \mathrm{~h}$ under a flow of $5 \% \mathrm{O}_{2} / \mathrm{Ar}\left(40 \mathrm{~mL} \mathrm{~min}^{-1}\right)$, before the reaction mixture, containing $0.5 \% \mathrm{CH}_{4}, 10 \% \mathrm{O}_{2}, 5 \% \mathrm{Ne}$ (used as internal standard) and $84.5 \% \mathrm{Ar}$, was added to the reactor. The total flow was maintained at $180 \mathrm{~mL} \mathrm{~min}^{-1}$, giving a gas hourly space velocity (GHSV) of $100,000 \mathrm{~mL} \mathrm{~g}^{-1} \mathrm{~h}^{-1}$.

The stability of all catalysts was tested using the same conditions as given above but the temperature was maintained at $300{ }^{\circ} \mathrm{C}$ for 35 hours, except for the Pd,Pt, $\mathrm{TiO}_{2} / \mathrm{H}-\mathrm{ZSM}-5$ (80) material, which was tested for 50 hours.

To evaluate the catalysts in the presence of water, the reaction stream was passed through a water saturator at a temperature to give a composition of $0.48 \% \mathrm{CH}_{4}, 9.5 \% \mathrm{O}_{2}, 4.8 \% \mathrm{Ne}, 80.5 \% \mathrm{Ar}$ and $4.8 \% \mathrm{H}_{2} \mathrm{O}\left(9 \mathrm{~mL} \mathrm{~min}^{-1}\right)$, and a GHSV of $105000 \mathrm{~mL} \mathrm{~h}^{-1} \mathrm{~g}^{-1}$. The products were analysed by on-line gas chromatography (GC) using an Agilent 7820A GC equipped with a methanizer, a TCD and a Flame lonisation Detector (FID) using a PoraPlotQ column. Under the conditions used, an exotherm was observed due to the exothermic nature of the methane combustion reaction, in which a temperature gradient of up to $10{ }^{\circ} \mathrm{C}$ was found between the centres of the furnace and the catalyst bed at high conversions.

Rates of reaction were measured at steady temperatures from $500{ }^{\circ} \mathrm{C}$ to $200{ }^{\circ} \mathrm{C}$. The percentage methane conversion was calculated based on the flow rates of reacted and unreacted methane. All activity data were measured under dry conditions unless otherwise stated.

$$
\% \text { conversion }=\frac{\left(\frac{F_{C H_{4}, i n}\left(\mathrm{molmin}^{-1}\right)}{F_{\mathrm{Ne}}\left(\mathrm{molmin}^{-1}\right)}\right)-\left(\frac{F_{\mathrm{CH}_{4}, \mathrm{out}}\left(\mathrm{molmin}^{-1}\right)}{F_{\mathrm{Ne}}\left(\mathrm{molmin}^{-1}\right)}\right)}{\left(\frac{F_{\mathrm{CH}_{4}, \mathrm{in}}\left(\mathrm{molmin}^{-1}\right)}{F_{\mathrm{Ne}}\left(\mathrm{molmin}^{-1}\right)}\right)}
$$

\section{Results and discussion}

\subsection{Catalyst Activity}

The activities of the catalysts prepared using ZSM-5, mordenite and beta zeolites with different $\mathrm{SiO}_{2}: \mathrm{Al}_{2} \mathrm{O}_{3}$ ratios were tested for 


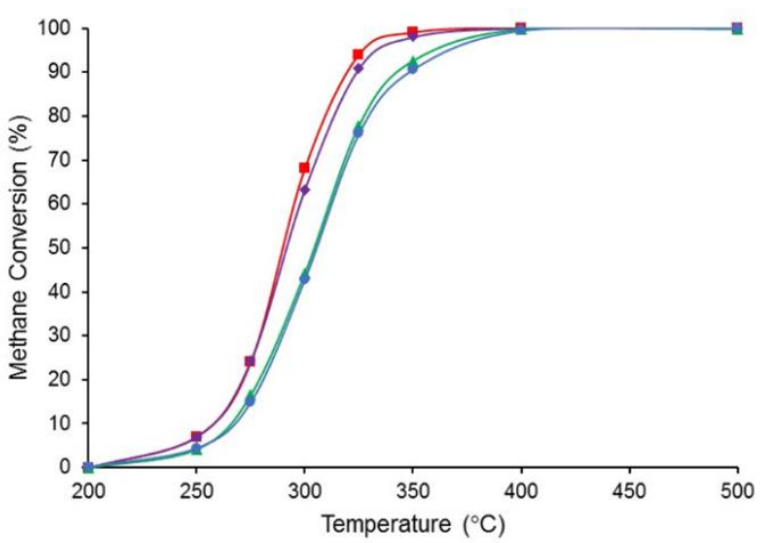

Figure 1. Catalytic activity profiles for methane oxidation over catalysts prepared on $\mathrm{H}-\mathrm{ZSM}-5$ supports with different $\mathrm{SiO}_{2}: \mathrm{Al}_{2} \mathrm{O}_{3}$ ratios: $\mathrm{Pd}, \mathrm{Pt}, \mathrm{TiO}_{2} / \mathrm{H}-\mathrm{ZSM}-5$ (23) (•), $\mathrm{Pd}, \mathrm{Pt}, \mathrm{TiO}_{2} / \mathrm{H}-\mathrm{ZSM}-5$ (30) ( $\Delta$ ), Pd,Pt,TiO $/$ /H-ZSM-5 (50) ( $\bullet$ ), Pd,Pt,TiO $/$ /H-ZSM-5 (80) (घ). Nominal composition: 5 wt.\% Pd, 2 wt.\% Pt, 17.5 wt.\% $\mathrm{TiO}_{2}$ on 75.5 wt.\%. zeolite.

methane combustion. The only products observed by $\mathrm{GC}$ analysis of the outlet stream of the reactor were $\mathrm{CO}_{2}$ and $\mathrm{H}_{2} \mathrm{O}$ and a carbon balance higher than $99 \%$ was obtained.

The activity profiles for the catalysts prepared using ZSM-5 supports are shown in Figure 1 and the data summarised in Table 1 . The catalysts prepared from the ZSM-5 supports were all active for total methane oxidation and all achieved complete conversion at $400{ }^{\circ} \mathrm{C}$. The $\mathrm{Pd}, \mathrm{Pt}, \mathrm{TiO}_{2} / \mathrm{H}-\mathrm{ZSM}-5$ (23) catalyst showed the lowest activity of the catalysts tested with a temperature for $50 \%$ conversion $\left(\mathrm{T}_{50 \%}\right)$ of $306^{\circ} \mathrm{C}$. However the activity of the catalysts increased with increasing $\mathrm{SiO}_{2}: \mathrm{Al}_{2} \mathrm{O}_{3}$ ratio in the support, with the $\mathrm{T}_{50 \%}$ decreasing to $304^{\circ} \mathrm{C}$ and 292 ${ }^{\circ} \mathrm{C}$ for the $\mathrm{Pd}, \mathrm{Pt}, \mathrm{TiO}_{2} / \mathrm{HZSM}-5$ (30) and (50) catalysts respectively and $\mathrm{Pd}, \mathrm{Pt}, \mathrm{TiO}_{2} / \mathrm{H}-\mathrm{ZSM}-5$ (80) showed the highest activity of the H-ZSM-5 supported catalysts, with a $\mathrm{T}_{50 \%}$ of $290{ }^{\circ} \mathrm{C}$ and complete conversion around $350{ }^{\circ} \mathrm{C}$. These differences are clearly seen when considering the conversion obtained at 300 ${ }^{\circ} \mathrm{C}$ being 43, 45, 63 and $68 \%$ for the $\mathrm{Pd}, \mathrm{Pt}, \mathrm{TiO}_{2} / \mathrm{H}-\mathrm{ZSM}-5$ (23), (30), (50) and (80) catalysts, respectively.

The activity profiles for the catalysts prepared from the mordenite and beta zeolite topologies are compared with the $\mathrm{Pd}, \mathrm{Pt}, \mathrm{TiO}_{2} / \mathrm{H}-\mathrm{ZSM}-5$ (30) catalyst in Figure 2 and the data summarised in Table 1 . Comparison of the three zeolite topologies tested shows the mordenite to be the most active, followed by the beta and the ZSM- 5 with $\mathrm{T}_{50 \%}$ of $289^{\circ} \mathrm{C}, 298^{\circ} \mathrm{C}$ and $304{ }^{\circ} \mathrm{C}$ respectively. It has been assumed that the small difference in the $\mathrm{SiO}_{2}: \mathrm{Al}_{2} \mathrm{O}_{3}$ ratios of the catalysts shown here, similar to the $\mathrm{Pd}, \mathrm{Pt}, \mathrm{TiO}_{2} / \mathrm{H}-\mathrm{ZSM}-5$ (23) and $\mathrm{Pd}, \mathrm{Pt}, \mathrm{TiO}_{2} / \mathrm{H}-\mathrm{ZSM}-5$ (30) catalysts shown in Figure 1, is not responsible for the differences in the activity observed. To further understand the role of acidity and the location of the metals on the activity of

Table 1. The temperature required to reach $10 \%\left(\mathrm{~T}_{10 \%}\right), 50 \%\left(\mathrm{~T}_{50 \%}\right)$ and $90 \%\left(\mathrm{~T}_{90 \%}\right)$ conversion for the combustion of methane using catalysts prepared on different zeolite supports.

\begin{tabular}{cccc}
\hline Catalyst & $\mathrm{T}_{10 \%}\left({ }^{\circ} \mathrm{C}\right)$ & $\mathrm{T}_{50 \%}\left({ }^{\circ} \mathrm{C}\right)$ & $\mathrm{T}_{90 \%}\left({ }^{\circ} \mathrm{C}\right)$ \\
\hline $\mathrm{Pd}, \mathrm{Pt}, \mathrm{TiO}_{2} / \mathrm{H}-\mathrm{ZSM}-5(23)$ & 268 & 306 & 348 \\
$\mathrm{Pd}, \mathrm{Pt}, \mathrm{TiO}_{2} / \mathrm{H}-\mathrm{ZSM}-5(30)$ & 266 & 304 & 342 \\
$\mathrm{Pd}, \mathrm{Pt}, \mathrm{TiO}_{2} / \mathrm{H}-\mathrm{ZSM}-5(50)$ & 258 & 292 & 324 \\
$\mathrm{Pd}, \mathrm{Pt}, \mathrm{TiO}_{2} / \mathrm{H}-\mathrm{ZSM}-5(80)$ & 258 & 290 & 319 \\
$\mathrm{Pd}, \mathrm{Pt}, \mathrm{TiO}_{2} / \mathrm{H}-\mathrm{MOR}(20)$ & 257 & 289 & 314 \\
$\mathrm{Pd}, \mathrm{Pt}, \mathrm{TiO}_{2} / \mathrm{H}-\mathrm{BEA}(38)$ & 264 & 298 & 334 \\
\hline
\end{tabular}

4 | J. Name., 2012, 00, 1-3

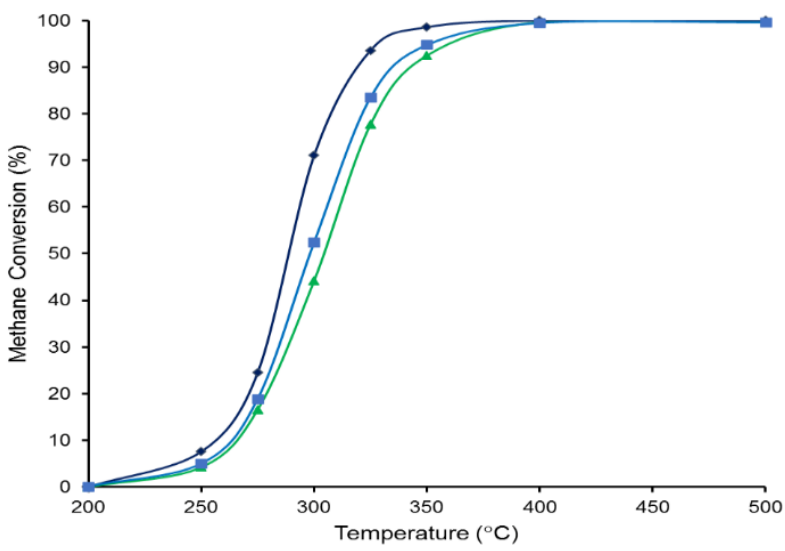

Figure 2. Catalytic activity profiles for methane oxidation over catalysts prepared on different supports Pd,Pt, $\mathrm{TiO}_{2} / \mathrm{H}-\mathrm{ZSM}-5(30)(\Delta), \mathrm{Pd}, \mathrm{Pt}, \mathrm{TiO}_{2} / \mathrm{H}-\mathrm{MOR}(20)(\diamond)$, and $\mathrm{Pd}, \mathrm{Pt}, \mathrm{TiO}_{2} / \mathrm{H}-\mathrm{BEA}$ (38) (口). Nominal composition: 5 wt.\% Pd, 2 wt.\% Pt, 17.5 wt.\% $\mathrm{TiO}_{2}$ on 75.5 wt.\% zeolite.

the catalysts, a range of characterisation techniques were used.

\subsection{Catalyst characterization}

\subsubsection{Physical Properties}

The surface areas and pore volumes of the catalysts as determined by BET analysis ${ }^{20}$ as well as the loading of palladium and platinum as determined by ICP-AES are summarized in Table 2. The measured surface areas of the supports (entries 14) are consistent with those provided by Alfa Aesar. ${ }^{24}$ As expected, the surface area of the zeolite decreased from between 413 and $432 \mathrm{~m}^{2} \mathrm{~g}^{-1}$ to 312 and $337 \mathrm{~m}^{2} \mathrm{~g}^{-1}$ and similarly the micropore volume decreased from between 0.11 and 0.13 $\mathrm{cm}^{3} \mathrm{~g}^{-1}$ to 0.07 and $0.08 \mathrm{~cm}^{3} \mathrm{~g}^{-1}$ on addition of $\mathrm{Pd}, \mathrm{Pt}$ and $\mathrm{TiO}_{2}$ (entries 6-9). The metal loading as measured by ICP-AES was found to be similar to the desired loading, being between 5.3 and 5.4 and 2.2 and 2.7 wt.\%, for Pd and Pt respectively. Values shown in entries 6-9 show only a slight variation in surface area, pore volume and metal loading among the four catalysts meaning differences in activity are unlikely to be attributed to these properties.

Table 2. Surface areas, micropore volumes and Pd and Pt loadings of the supports and catalysts

\begin{tabular}{|c|c|c|c|c|c|}
\hline Entry & Sample & $\begin{array}{c}\text { BET } \\
\text { surface } \\
\text { area } \\
\left(\mathrm{m}^{2} \mathrm{~g}^{-1}\right)^{\mathrm{a}}\end{array}$ & $\begin{array}{l}\text { Micropor } \\
\text { e volume } \\
\left(\mathrm{cm}^{3} \mathrm{~g}^{-1}\right)^{\mathrm{b}}\end{array}$ & $\begin{array}{l}\mathrm{Pd} \\
\text { wt. } \\
\%^{c}\end{array}$ & $\begin{array}{l}\text { Pt } \\
\text { wt. } \\
\%^{c}\end{array}$ \\
\hline 1 & ZSM-5 (23) & 413 & 0.11 & - & - \\
\hline 2 & ZSM-5 (30) & 426 & 0.11 & - & - \\
\hline 3 & ZSM-5 (50) & 432 & 0.12 & - & - \\
\hline 4 & ZSM-5 (80) & 430 & 0.13 & - & - \\
\hline 5 & $\mathrm{TiO}_{2}$ (anatase) & 45 & - & - & - \\
\hline 6 & $\mathrm{Pd}, \mathrm{Pt}, \mathrm{TiO}_{2} / \mathrm{H}-\mathrm{ZSM}-5$ (23) & 312 & 0.08 & 5.4 & 2.7 \\
\hline 7 & $\mathrm{Pd}, \mathrm{Pt}, \mathrm{TiO}_{2} / \mathrm{H}-\mathrm{ZSM}-5$ (30) & 317 & 0.07 & 5.4 & 2.6 \\
\hline 8 & $\mathrm{Pd}, \mathrm{Pt}, \mathrm{TiO}_{2} / \mathrm{H}-\mathrm{ZSM}-5$ (50) & 337 & 0.08 & 5.3 & 2.6 \\
\hline 9 & $\mathrm{Pd}, \mathrm{Pt}, \mathrm{TiO}_{2} / \mathrm{H}-\mathrm{ZSM}-5$ (80) & 330 & 0.07 & 5.3 & 2.2 \\
\hline $10^{d}$ & $\begin{array}{c}\text { Aged Pd,Pt, } \mathrm{TiO}_{2} / \mathrm{H}-\mathrm{ZSM}- \\
5(80)\end{array}$ & 317 & 0.07 & - & - \\
\hline
\end{tabular}

aestimated using the BET model with criteria proposed by Rouquerol et al. ${ }^{20}$ and described in ESI 1. ${ }^{b}$ calculated using t-plot method cdetermined using ICP-AES. dafter $50 \mathrm{~h}$ on stream at $300{ }^{\circ} \mathrm{C}$ 


\subsection{2 $\mathrm{NH}_{3}$-TPD}

The surface acidity of the zeolite supports and corresponding catalysts were studied by $\mathrm{NH}_{3}$-TPD and the results for $\mathrm{Pd}, \mathrm{Pt}, \mathrm{TiO} 2 / \mathrm{H}-\mathrm{ZSM}-5$ (23) are illustrated in Figure 3 with the other catalysts shown in ESI 2 . The results are as expected with two broad peaks observed for the zeolite supports at low temperature (LT - below $300{ }^{\circ} \mathrm{C}$ ) and high temperature (HTabove $300{ }^{\circ} \mathrm{C}$ ). The LT peak can be deconvoluted into two components; component 1 (blue) at $150{ }^{\circ} \mathrm{C}$ which is attributed to the $\mathrm{NH}_{3}$ bound via hydrogen bonding to an $\mathrm{NH}_{4}{ }^{+}$ion formed by $\mathrm{NH}_{3}$ and $\mathrm{Br} \varnothing$ nsted acid sites and component 2 (green) at 200 ${ }^{\circ} \mathrm{C}$, which is attributed to the weakly bound $\mathrm{NH}_{3}$ to weak Lewis acid sites [25]. On the other hand, the HT peak can be fitted using only one component, component 5 (purple) at ca. $380{ }^{\circ} \mathrm{C}$, which corresponds to $\mathrm{NH}_{3}$ desorbed from the strong Brønsted acid sites. ${ }^{25,} 26$

Compared to the supports alone, two extra components were found in the TPD profile of the catalysts, namely component 3 (light blue) at ca. $240{ }^{\circ} \mathrm{C}$ and 4 (orange) at around $340^{\circ} \mathrm{C}$ (Figure $3)$. The surface acidity of $\mathrm{Pd} / \mathrm{TiO}_{2}$ catalysts was studied by Gonzalez et al., and a desorption peak was found at around 238 ${ }^{\circ} \mathrm{C}$ in the $\mathrm{NH}_{3}$-TPD profiles of these samples. ${ }^{27}$ Lou et al. employed pyridine Fourier-transform infrared spectroscopy (FT-IR) to study $\mathrm{Pd} / \mathrm{H}-\mathrm{ZSM}-5$ materials and subsequently assigned a peak at $c a .300{ }^{\circ} \mathrm{C}$ to strong Lewis acid sites derived from the coordinatively unsaturated Pd atoms, which, in turn, are the products from the interaction between the highly dispersed $\mathrm{PdO}_{x}$ and the $\mathrm{Br} \varnothing$ nsted acid sites on the surface of ZSM-5. ${ }^{10} \mathrm{TiO}_{2}$ in the anatase form was shown to possess a certain degree of acidity. However this is not thought to contribute strongly to the profile as the amount of acid sites in anatase $\mathrm{TiO}_{2}$ is small $\left(0.042 \mathrm{mmol}\right.$ per gram of $\left.\mathrm{TiO}_{2}\right)$ compared to the values of components 3 and 4 shown in Table $3(\mathrm{mmol}$ per gram of the catalysts) and the temperature of desorption is also lower (around $200{ }^{\circ} \mathrm{C}$ ) ${ }^{28,29}$. Therefore, the components 3 and 4 have been assigned to the $\mathrm{NH}_{3}$ bound to $\mathrm{PdO}_{x} / \mathrm{PtO}_{x}$ species dispersed on $\mathrm{TiO}_{2}$ and $\mathrm{H}-\mathrm{ZSM}-5$ media.

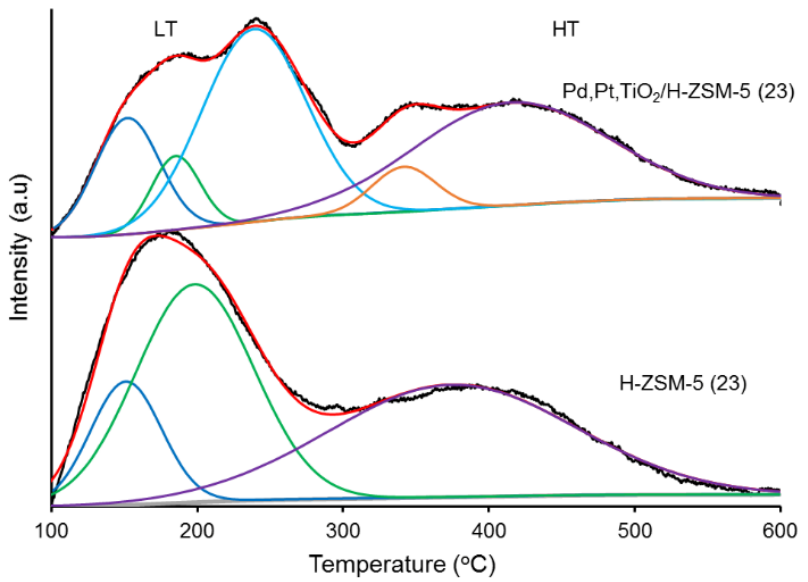

Figure 3. $\mathrm{NH}_{3}$-TPD profiles of $\mathrm{H}-\mathrm{ZSM}-5$ (23) and the corresponding $\mathrm{Pd}, \mathrm{Pt}, \mathrm{TiO}_{2} / \mathrm{H}$ ZSM-5 (23) catalyst. Colour codes: signal (black), fit (red), background (grey), and components 1-5 (blue, green, light blue, orange and purple, respectively)
Table 3. Quantification of different acid sites based on $\mathrm{NH}_{3}$-TPD analysis

\begin{tabular}{ccccccc}
\hline Samples & Com. & Com. & Com. & Com. & Com. & Total $^{2}$ \\
& $1^{1}$ & 2 & 3 & 4 & 5 & \\
\hline $\mathrm{H}-\mathrm{ZSM}-5(23)$ & 0.16 & 0.47 & - & - & 0.51 & 1.14 \\
$\mathrm{H}-\mathrm{ZSM}-5(30)$ & 0.09 & 0.42 & - & - & 0.38 & 0.89 \\
$\mathrm{H}-\mathrm{ZSM}-5(50)$ & 0.05 & 0.25 & - & - & 0.25 & 0.54 \\
$\mathrm{H}-\mathrm{ZSM}-5(80)$ & 0.04 & 0.19 & - & - & 0.21 & 0.44 \\
$\mathrm{Pd}, \mathrm{Pt}, \mathrm{TiO}{ }_{2} / \mathrm{H}-$ & 0.14 & 0.07 & 0.36 & 0.05 & 0.37 & 0.98 \\
ZSM-5(23) & & & & & & \\
$\mathrm{Pd}, \mathrm{Pt}, \mathrm{TiO} / \mathrm{H}-$ & 0.07 & 0.22 & 0.13 & 0.14 & 0.14 & 0.70 \\
ZSM-5(30) & & & & & & \\
$\mathrm{Pd}, \mathrm{Pt}, \mathrm{TiO} / \mathrm{H}-$ & 0.15 & 0.23 & 0.16 & 0.09 & 0.03 & 0.66 \\
ZSM-5(50) & & & & & & \\
$\mathrm{Pd}, \mathrm{Pt}, \mathrm{TiO} / \mathrm{H}-$ & 0.06 & 0.15 & 0.06 & 0.16 & 0.03 & 0.46 \\
ZSM-5(80) & & & & & & \\
\hline
\end{tabular}

${ }^{1}$ amount of $\mathrm{NH}_{3}$ desorbed corresponding to current component, in mmol g-1 ${ }^{-1}$ total amount of $\mathrm{NH}_{3}$ desorbed by the sample, in $\mathrm{mmol} \mathrm{g}^{-1}$

Quantitatively, the amount of desorbed $\mathrm{NH}_{3}$ listed in Table 3 shows the decrease in the number of stronger Brønsted acid sites (component 5) as the $\mathrm{SiO}_{2}: \mathrm{Al}_{2} \mathrm{O}_{3}$ ratio increases in both the unfunctionalized supports and in the supported catalysts. With the same $\mathrm{SiO}_{2}: \mathrm{Al}_{2} \mathrm{O}_{3}$ ratio, there is quite a significant decrease in the number of Lewis acid sites (component 2) and Brønsted acid sites (component 5 ) in the catalysts compared to the unfunctionalized supports. The same phenomena were observed in the work of Lou et al. and these decreases were later assigned to the removal of extra-framework aluminium and the occupancy of Brønsted acid sites by the basic $\mathrm{PdO}_{x}$ species, respectively. ${ }^{10}$

As can be seen in Table 1 and Table 3, the Pd,Pt,TiO $2 / \mathrm{H}-\mathrm{ZSM}-5$ (80) catalyst which contains the least number of acid sites led to the highest catalytic activity implying that the acidity of the catalysts does not reflect the observed catalytic activity and that the importance of acid sites in direct methane activation is not observed in the current work.

\subsubsection{XRD analysis}

XRD diffractograms for H-ZSM-5(80), Pd,Pt, $\mathrm{TiO}_{2} / \mathrm{H}-\mathrm{ZSM}-5$ (80), $2 \% \mathrm{Pt} / \mathrm{TiO}_{2} / \mathrm{H}-\mathrm{ZSM}-5$ (80), $5 \% \mathrm{Pd} / \mathrm{TiO}_{2} / \mathrm{H}-\mathrm{ZSM}-5$ (80), and the titania anatase component are shown in Figure 4.

Comparison of the diffractograms shown in Figure 4 shows that the zeolite support retains its crystallinity after the addition of the metallic components. The first two diffraction peaks in the catalysts and their supports at $2 \theta$ between $8^{\circ}$ and $10^{\circ}$ can be assigned to the (101) and (011) planes of the MFI (ZSM-5) phase, respectively. ${ }^{10}$

Diffraction peaks corresponding to crystalline $\mathrm{PdO}$ and to $\mathrm{TiO}_{2}$ in the anatase polymorph were determined and are marked, in Figure 4e. ${ }^{30,31}$ While no peak corresponding to $\mathrm{PtO}_{2}$ is observed in Figure $4 \mathrm{e}$, it is not possible to rule out the presence of PtO, since the reflections overlap with those of $\mathrm{PdO}$ because of their similar position. ${ }^{30,32}$

An additional reflection was detected at $2 \theta \sim 40^{\circ}$, which is not present in the diffractogram of $5 \% \mathrm{Pd} / \mathrm{TiO}_{2} / \mathrm{H}-\mathrm{ZSM}-5$ (80), the sample without Pt (Figure 4d). This reflection was observed in 


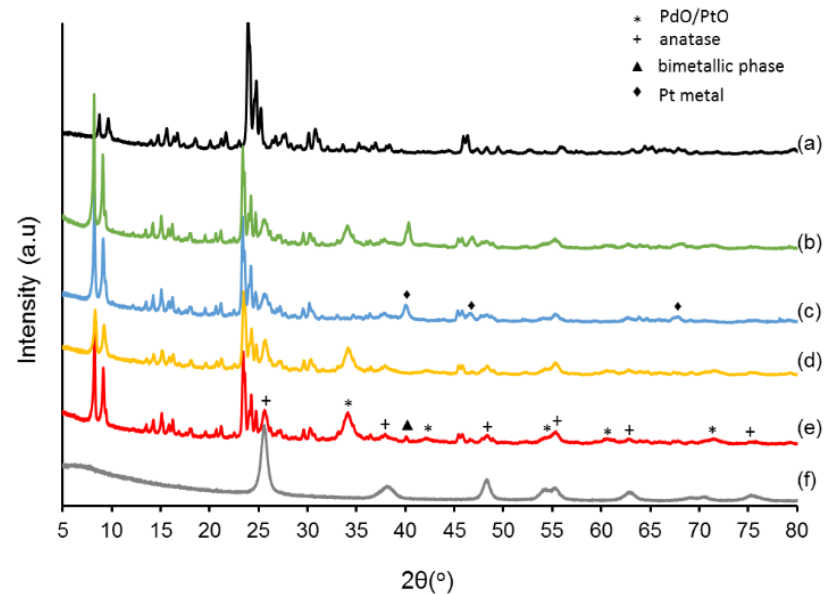

Figure 4. XRD diffractograms of the H-ZSM-5 (80) supported catalysts with ZSM-5 and $\mathrm{TiO}_{2}$ for reference. (a) H-ZSM-5 (80), (b) Pd, $\mathrm{Pt}, \mathrm{TiO}_{2} / \mathrm{H}-\mathrm{ZSM}-5$ (80) $\mathrm{H}_{2}$ pretreated, (c) $2 \% \mathrm{Pt}, \mathrm{TiO}_{2} / \mathrm{H}-\mathrm{ZSM}-5$ (80), (d) $5 \% \mathrm{Pd}, \mathrm{TiO}_{2} / \mathrm{H}-\mathrm{ZSM}-5$ (80), (e) Pd,Pt, $\mathrm{TiO}_{2} / \mathrm{H}-\mathrm{ZSM}$ $5(80)$ and (f) $\mathrm{TiO}_{2}$ (anatase). All catalysts contain 17.5 wt.\% $\mathrm{TiO}_{2}$ and 5 wt.\% Pd and 2wt.\% Pt where not stated.

each of the Pd,Pt, $\mathrm{TiO}_{2} / \mathrm{H}-\mathrm{ZSM}-5$ (80) catalysts and became more prominent in the $\mathrm{H}_{2}$ pretreated sample (Figure 4b), which confirms its metallic nature. This peak has previously been assigned to the 111 reflection of an alloy between $\mathrm{Pd}$ and $\mathrm{Pt}$, although due to the similarity of the unit cells of the Pd and Pt metallic phases, it is not a definitive proof for the existence of a bimetallic phase. ${ }^{30}, 33,34$ However, given its absence from the diffractograms of the monometallic Pd catalyst, from now on, this phase is referred to as the bimetallic phase of Pd and Pt.

The particle size of the $\mathrm{PdO}, \mathrm{TiO}_{2}$ and bimetallic components calculated from the XRD data using the Scherrer equation are given in Table 4. It can be seen that there is little variation observed in the crystallite size of $\mathrm{PdO}, \mathrm{TiO}_{2}$ and the bimetallic phase from one sample to another, especially taking into account the limit in accuracy of the analysis. ${ }^{35}$ The only exception is the case of the $\mathrm{Pd}, \mathrm{Pt}, \mathrm{TiO}_{2} / \mathrm{H}-\mathrm{MOR}$ (20) sample, in which the average crystallite size of the bimetallic phase is significantly smaller than those of the other samples. The similarity in particle size of $\mathrm{PdO}$ obtained with $\mathrm{H}-\mathrm{ZSM}-5$ supports of different $\mathrm{SiO}_{2}: \mathrm{Al}_{2} \mathrm{O}_{3}$ ratios will be later confirmed using STEMEDS, TEM and EXAFS analysis.

The ratio of the bimetallic phase peak to the PdO peak was taken as a measure of the proportion of the bimetallic species that was present compared with the metal oxide ( $\mathrm{PdO}$ or PtO). Table 4 shows that for the catalysts prepared using the MFI zeolite, this metal:oxide ratio increases with increasing $\mathrm{SiO}_{2}: \mathrm{Al}_{2} \mathrm{O}_{3}$ ratio, in line with the increasing activity of these catalysts. To determine if this was also applicable to other zeolite structures, a similar analysis was carried out with the catalysts prepared using the mordenite and beta supports. Figure 5 shows that there is a correlation between the ratio of the amount of bimetallic phase compared to the amount of $\mathrm{PdO}$ and the activity of the catalysts, with catalysts containing a higher proportion of the bimetallic phase and a lower proportion of oxide being the more active.
Table 4. Summary of crystallite sizes for $\mathrm{PdO}, \mathrm{TiO}_{2}$ and bimetallic phases and relative peak areas determined by XRD.

\begin{tabular}{|c|c|c|c|c|}
\hline \multirow{2}{*}{ Catalyst } & \multicolumn{3}{|c|}{ Average crystallite size $(\mathrm{nm})^{*}$} & \multirow{2}{*}{$\begin{array}{c}\text { Bimetallic } \\
\text { /PdO peak } \\
\text { area ratio** }\end{array}$} \\
\hline & $\mathrm{PdO}$ & $\mathrm{TiO}_{2}$ & Bimetallic & \\
\hline $\begin{array}{c}\mathrm{Pd}, \mathrm{Pt}, \mathrm{TiO}_{2} / \mathrm{H}-\mathrm{ZSM}- \\
5(23)\end{array}$ & 5.7 & 13.2 & 39.9 & 0.024 \\
\hline $\begin{array}{c}\mathrm{Pd}, \mathrm{Pt}, \mathrm{TiO}_{2} / \mathrm{H}-\mathrm{ZSM}- \\
5(30)\end{array}$ & 6.8 & 12.7 & 39.4 & 0.032 \\
\hline $\begin{array}{c}\mathrm{Pd}, \mathrm{Pt}, \mathrm{TiO}_{2} / \mathrm{H}-\mathrm{ZSM}- \\
5(50)\end{array}$ & 6.9 & 11.0 & 36.8 & 0.051 \\
\hline $\begin{array}{c}\mathrm{Pd}, \mathrm{Pt}, \mathrm{TiO}_{2} / \mathrm{H}-\mathrm{ZSM}- \\
5(80)\end{array}$ & 7.6 & 12.5 & 38.1 & 0.062 \\
\hline $\begin{array}{c}\mathrm{Pd}, \mathrm{Pt}, \mathrm{TiO}_{2} / \mathrm{H}- \\
\operatorname{MOR}(20)\end{array}$ & 7.0 & 12.6 & 28.2 & 0.064 \\
\hline $\mathrm{Pd}, \mathrm{Pt}, \mathrm{TiO}_{2} / \mathrm{H}-\mathrm{BEA}(38)$ & 7.0 & 12.7 & 40.3 & 0.038 \\
\hline
\end{tabular}

* calculated using Scherrer equation applying to the $\mathrm{PdO}(101)$ peak at $\sim 34^{\circ}$, the $\mathrm{TiO}_{2}$ (101) peak at $\sim 25^{\circ}$, and the bimetallic peak at $\sim 40^{\circ}$; the peak width at halfheight was determined by fitting the experimental data using the program Highscore Plus. ${ }^{* *}$ the ratio of the peak area between the bimetallic peak at $40^{\circ}$ and $\mathrm{PdO}(101)$ at $~ 34^{\circ}$.

\subsubsection{STEM and electron tomography}

To further study the particle size of the crystallites and to confirm the location of the different metals, the catalysts were characterised using STEM-HAADF and STEM-EDS.

High-resolution HAADF-STEM images (Figure 6) reveal the structure of the catalyst. Nanoparticles rich in $\mathrm{Pd} / \mathrm{Pt}$ stand out as bright spots due to their significantly higher atomic number compared with those of the other components. Anatase (100) and ZSM- 5 were also clearly identified based on their observed lattice spacings and crystal structures.

The particle size distribution of Pd/Pt rich nanoparticles was measured from the HAADF-STEM images and is shown in Figures $6 \mathrm{c}$ and $6 \mathrm{f}$. The presence of the oxide support makes it difficult to distinguish crystallographic information in these particles, and therefore the distributions shown here represent

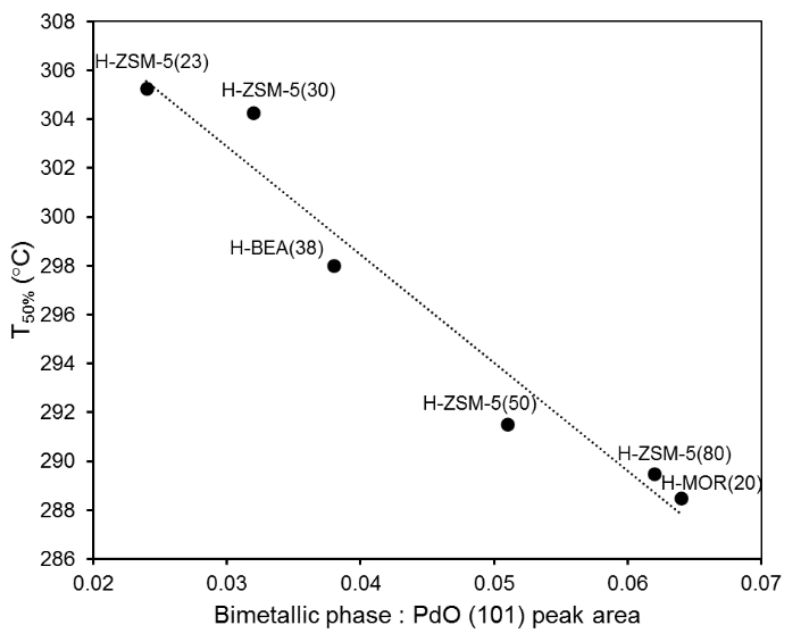

Figure 5. Correlation between the ratio of the peak area for the peak associated with the bimetallic phase (at $\sim 40^{\circ}$ ) to the peak associated with PdO (at $\sim 34{ }^{\circ}$ ), against the activity of the catalyst as given by $T_{50 \%}$. Each point is labelled with the name of the zeolite support. 

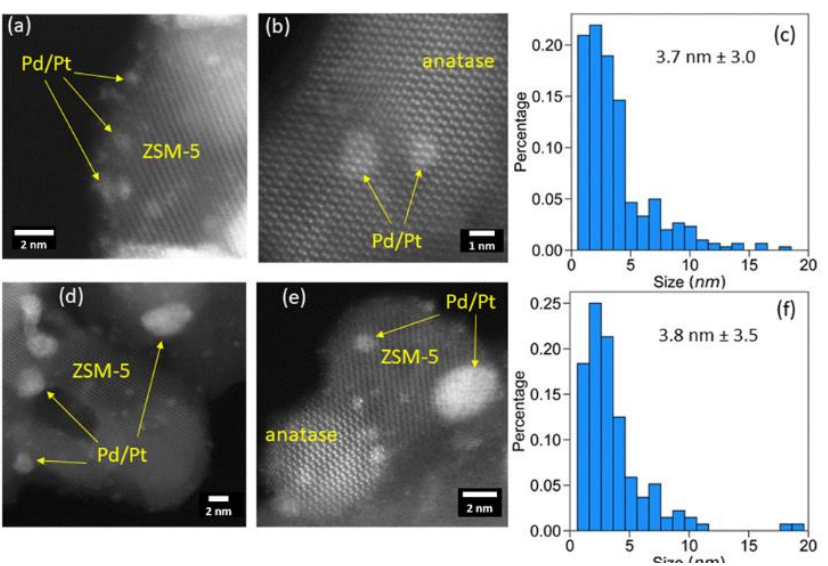

Figure 6. High-resolution STEM-HAADF images and $\mathrm{Pd} / \mathrm{Pt}$ particle size distribution charts for Pd/Pt/TiO $/ \mathrm{H}-\mathrm{ZSM}-5$ (23) (a, b and c) and $\mathrm{Pd} / \mathrm{Pt} / \mathrm{TiO}_{2} / \mathrm{H}$ ZSM-5 (80) (d, e and f).

both Pd and Pt rich particles (identified as such from the relatively high scattering cross section of these two metals). Average particle sizes of $3.7 \pm 3 \mathrm{~nm}$ and $3.8 \pm 3.5 \mathrm{~nm}$ are found for the Pd,Pt, TiO $/$ /H-ZSM-5 (23) and Pd,Pt, TiO $/ \mathrm{H}-\mathrm{ZSM}-5$ (80) catalysts, respectively showing a negligible difference in particle size of $\mathrm{Pd} / \mathrm{Pt}$ on the two supports. Comparison with the XRD Scherrer analysis suggests that these particles are likely to be $\mathrm{PdO}$ and $\mathrm{PtO}$. Thus, the noticeable difference in catalytic activity between $\mathrm{Pd} / \mathrm{Pt} / \mathrm{TiO}_{2} / \mathrm{H}-\mathrm{ZSM}-5$ (23) and $\mathrm{Pd} / \mathrm{Pt} / \mathrm{TiO} \mathrm{O}_{2} / \mathrm{H}-\mathrm{ZSM}-5$ (80) shown in Figure 1 is unlikely to result from the difference in the $\mathrm{Pd} / \mathrm{Pt}$ dispersion found in the two catalysts. STEM-HAADF and the corresponding STEM-EDS elemental maps of $\mathrm{Pd}, \mathrm{Pt}, \mathrm{TiO}_{2} / \mathrm{HZSM}-5$ (23) and $\mathrm{Pd}, \mathrm{Pt}, \mathrm{TiO}_{2} / \mathrm{HZSM}-5$ (80) catalysts are shown in Figures $7(a-h)$. The brighter contrast in the STEMHAADF images is confirmed to correspond to areas rich in $\mathrm{Pd}$ and Pt (Figures 7a and 7e), while the $\mathrm{TiO}_{2}$ and $\mathrm{ZSM}-5$ support areas have weaker HAADF intensity and produce the expected $\mathrm{Ti}$ and $\mathrm{O}$ or $\mathrm{Si}$ and $\mathrm{O} \mathrm{X}$-ray counts respectively (see ESI Figures S3 and S4). The STEM-EDS data demonstrates the presence of highly dispersed $\mathrm{Pd}$ and $\mathrm{Pt}$ rich particles in the catalyst which are mostly co-located revealing an intimate mixing of $\mathrm{Pd}$ and $\mathrm{Pt}$ (Figures $7 \mathrm{~b}-\mathrm{d}, 7 \mathrm{f}-\mathrm{h}$, and $7 \mathrm{j}-\mathrm{I}$ ). Comparison of the Ti and Si STEMEDS elemental maps allows the zeolite and anatase support particles to be clearly separated (Figure S3 and S4). Figure S3 shows that $\mathrm{TiO}_{2}$ was deposited around the outside of the zeolite support and the $\mathrm{TiO}_{2}$ particle size is consistent with the average crystallite size of $13 \mathrm{~nm}$ measured by XRD (Table 4), which is much larger than the ZSM-5 pore size ( $\sim 0.5 \mathrm{~nm})$. The Pd and Pt nanoparticles were found to be deposited on both ZSM- 5 and $\mathrm{TiO}_{2}$, as well as at the interface between the two materials, (Figure S3 and Figure S4). However, careful inspection of 15 regions of the $\mathrm{Pd} / \mathrm{Pt} / \mathrm{TiO}_{2} / \mathrm{HZSM}-5$ (23) and $\mathrm{Pd} / \mathrm{Pt} / \mathrm{TiO}{ }_{2} / \mathrm{HZSM}-5$ (80) catalysts revealed a slight preference for the metal catalyst to be associated with the $\mathrm{TiO}_{2}$ rather than the zeolite; $47 \%$ of the regions studied had $\mathrm{Pd} / \mathrm{Pt}$ preferentially located on the $\mathrm{TiO}_{2}$ particles, while the metals were equally distributed for $40 \%$ of the regions, and preferentially located on the zeolite in $13 \%$ of regions.
This is perhaps surprising given the higher surface area of zeolite available, but may be due to the difference in the point of zero charge between $\mathrm{TiO}_{2}$ and $\mathrm{ZSM}-5$ (anatase $\mathrm{TiO}_{2}$ is reported to be $4.2^{36}$ while $\mathrm{H}-\mathrm{ZSM}-5$ with a $\mathrm{SiO}_{2}: \mathrm{Al}_{2} \mathrm{O}_{3}$ ratio of 30 is reported to be $5.0^{37}$ ). The nanoparticle location and morphology of the catalysts was further studied using STEM-HAADF electron tomography, Figure 8. Figure 8a shows surface-rendered representations of the segmented reconstructed volume of $\mathrm{Pd}, \mathrm{Pt}, \mathrm{TiO}_{2} / \mathrm{H}-\mathrm{ZSM}-5$ (23). Here, the small red volumes, correspond to the high intensity areas of the HAADF images, that is, to the $\mathrm{Pd} / \mathrm{Pt}$ rich nanoparticles; while the region in blue corresponds to a $\mathrm{TiO}_{2}$ support particle. A key feature which can be extracted from the $3 \mathrm{D}$ tomographic data in Figure $8 \mathrm{a}$, is the location of the $\mathrm{Pd} / \mathrm{Pt}$ nanoparticles on the $\mathrm{TiO}_{2}$. $2 \mathrm{D}$ slices through the $3 \mathrm{D}$ reconstructed volume shown in Figures $8 \mathrm{~d}-8 \mathrm{f}$ reveals the porous structure of the $\mathrm{TiO}_{2}$ support and the location of $\mathrm{Pd} / \mathrm{Pt}$ nanoparticles inside and on the surface. The majority of the $\mathrm{Pd} / \mathrm{Pt}$ particles were found on the external surface of $\mathrm{TiO}_{2}$, but, there are also some particles ( 2 out of total 15 particles) located inside the $\mathrm{TiO}_{2}$ support. It was observed that some pores in the $\mathrm{TiO}_{2}$ are not connected to the outer surface, and hence nanoparticles that are located on these surfaces are not likely to be involved in the catalytic reaction.

A second tomographic data set for $\mathrm{Pd} / \mathrm{Pt} / \mathrm{TiO}_{2} / \mathrm{H}-\mathrm{ZSM}-5$ (23) in which all components ( $\mathrm{Pd} / \mathrm{Pt}$ nanoparticles, $\mathrm{TiO}_{2}$ and zeolite) are visible is shown in ESI 4 (Figure S5). Again, the majority of Pd/Pt particles are located on the external surface of the $\mathrm{TiO}_{2}$ and, additionally, the $\mathrm{TiO}_{2}$ particles were found on the external surface of the zeolite (consistent with the 2D STEM-EDS data in Figure S3). However, it is worth noting that these tomographic data sets have a voxel resolution of $\sim 0.5 \mathrm{~nm}$, so it is not possible to detect the smallest nanoparticles, $<0.5 \mathrm{~nm}$, which may be located inside the pores of ZSM-5. A similar reconstruction for high $\mathrm{SiO}_{2}: \mathrm{Al}_{2} \mathrm{O}_{3}$ ratio sample $\mathrm{Pd}, \mathrm{Pt}, \mathrm{TiO}_{2} / \mathrm{H}-\mathrm{ZSM}-5$ (80) is shown in ESI 4 (Figure S6) demonstrating that the size distributions and location of the $\mathrm{Pd} / \mathrm{Pt}$ nanoparticles was found to be similar in the two samples despite their different $\mathrm{SiO}_{2}: \mathrm{Al}_{2} \mathrm{O}_{3}$ ratios.
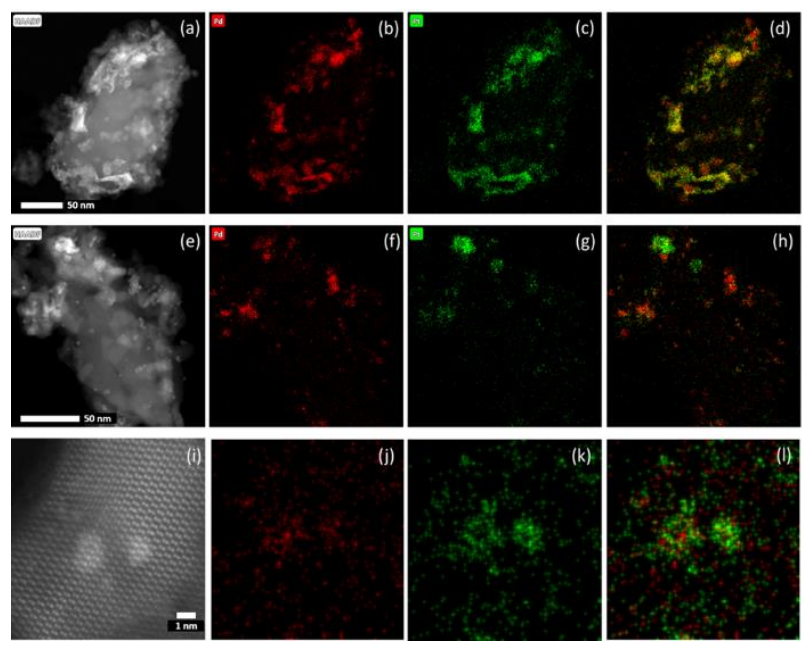

Figure 7. STEM HAADF images (left hand column), individual Pd (red) and Pt (green) EDS elemental maps and composite $\mathrm{Pd}+\mathrm{Pt}$ overlay image (where red and green combine to yellow). (a-d) and ( $\mathrm{i}-\mathrm{I})$ are the $\mathrm{Pd}, \mathrm{Pt}, \mathrm{TiO}_{2} / \mathrm{H}-\mathrm{ZSM}-5$ (23) sample, (e-h) is the $\mathrm{Pd}, \mathrm{Pt}, \mathrm{TiO}_{2} / \mathrm{ZSM}-5(80)$ catalyst. The red indicates $\mathrm{Pd}$ and the green Pt elements with the yellow indicating areas where Pd and Pt are co-located. 


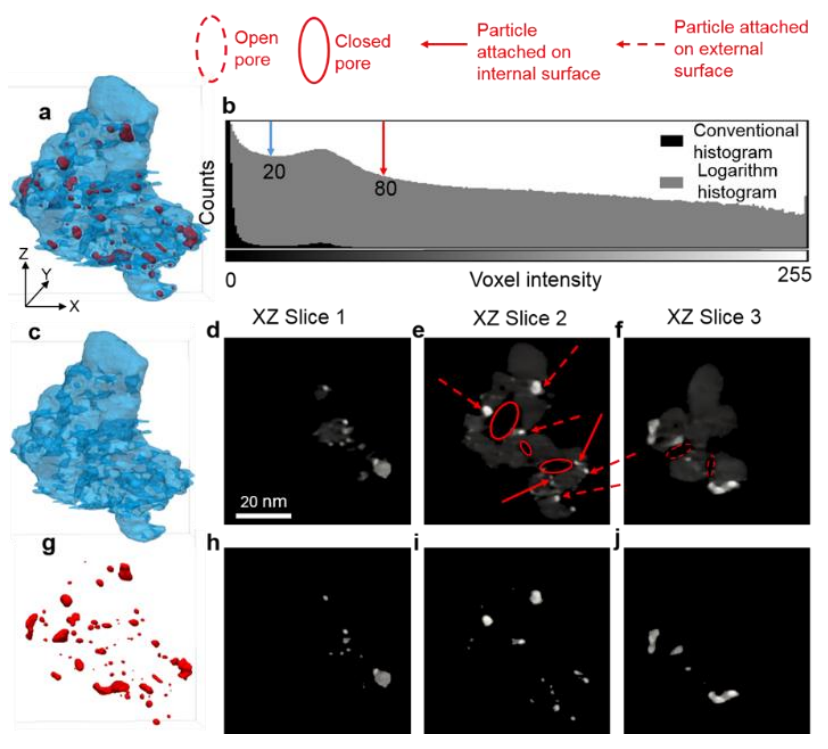

Figure 8. $3 D$ visualisation and $2 D$ orthoslices from STEM-HAADF electron tomography reconstruction of the $\mathrm{Pd}, \mathrm{Pt}, \mathrm{TiO}_{2} / \mathrm{H}-\mathrm{ZSM}-5$ (23) catalyst a) 3D surface render of the reconstruction with colours indicating intensity differences, blue, low HAADF intensity ( $\mathrm{TiO}_{2}$ particle), red, high HAADF intensity (Pd and Pt rich particle). b) histogram of the unprocessed reconstruction. Voxel intensities ranging from 20255 are rendered blue $\left(\mathrm{TiO}_{2}\right.$ support, shown in c) while intensities of 80-255 are rendered red ( $\mathrm{Pd}$ and $\mathrm{Pt}$ rich particles, shown in $\mathrm{g}$ ). $\mathrm{d}-\mathrm{f}$ ) and $\mathrm{h}-\mathrm{j}$ ) are $2 \mathrm{D}$ slices extracted from c) and g) respectively. Legend above refers to the annotations in e and $f$.

\subsubsection{XAS}

The XANES spectra of the three catalysts, $\mathrm{Pd}, \mathrm{Pt}, \mathrm{TiO}_{2} / \mathrm{HZSM}-5$ $(23,50,80)$ and the reference materials $\mathrm{PdO}, \mathrm{PtO}_{2}$ and $\mathrm{Pd}, \mathrm{Pt}$ metals at the Pd K-edge and the Pt $\mathrm{L}_{\| 11}$-edge are shown in Figure 9.

It can be immediately seen that the Pd XANES spectra of the catalysts are more similar to those of the corresponding oxide, $\mathrm{PdO}$, rather than that of the metal, Pd foil, indicating that the $\mathrm{Pd}$ is present predominantly as oxides. Furthermore, looking closely at both the position of the adsorption edge and intensity of the "white line" peak indicates the average oxidation state of $\mathrm{Pd}$ in the three catalysts as being significantly higher than that of the Pd foil reference. The slight shift in the edge position and the slight increase in the intensity of the "white line" peak in the $\mathrm{Pd}, \mathrm{Pt}, \mathrm{TiO}_{2} / \mathrm{H}-\mathrm{ZSM}-5(23,50,80)$ samples compared to those of the $\mathrm{PdO}$ reference suggests that the samples consist of $\mathrm{PdO}$ but that the local Pd environment is not the same as the reference. At the Pt LIII-edge, by comparing the intensity of the "white line" peaks, the average oxidation state of $\mathrm{Pt}$ is estimated to be between those of $\mathrm{PtO}_{2}$ and $\mathrm{Pt}$ foil references (Figure 9b). Moreover, there is hardly any difference in the oxidation states of $\mathrm{Pd}$ and $\mathrm{Pt}$ supported on $\mathrm{H}-\mathrm{ZSM}-5$ with different $\mathrm{SiO}_{2}: \mathrm{Al}_{2} \mathrm{O}_{3}$ ratios.

Figure 10 shows the EXAFS measured at the Pd K-edge of the three catalysts and for PdO and Pd foil as references. In agreement with the XANES results, EXAFS data shows the similarities between the spectra for the three catalysts with that of the PdO reference. Specifically, there are two main peaks that can be observed in the Fourier transform spectra in R-space

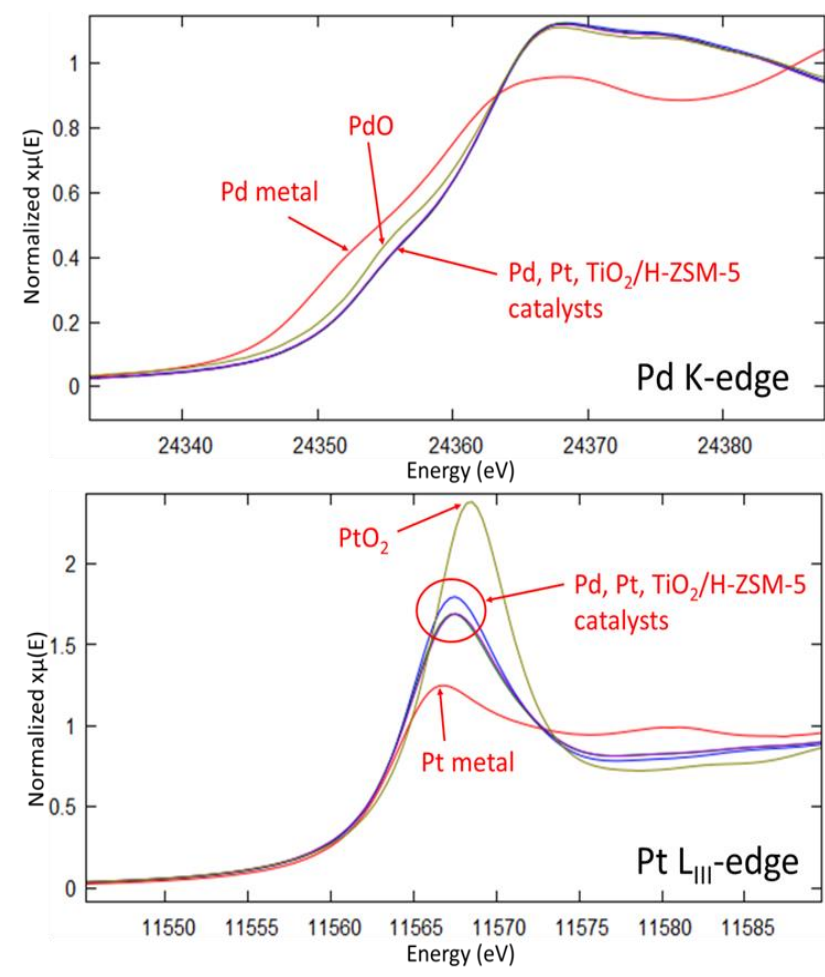

Figure 9. XANES at the Pd K-edge and the Pt LIII-edge of the three catalysts $\mathrm{Pd}, \mathrm{Pt}, \mathrm{TiO}_{2} / \mathrm{H}-\mathrm{ZSM}-5$ (23 (blue), 50 (purple), 80 (green)) and $\mathrm{PdO}$ (yellow), $\mathrm{PtO}_{2}$ (yellow) and $\mathrm{Pd}$ (red) and Pt metal (red) references.

of the three catalysts and PdO reference. The first peak presents at an uncorrected distance of $1.6 \AA$, which corresponds to the first Pd-O shell. The second peak, spanning between 2.1 and 3.5 $\AA$, is a combination of the contributions from the second and third Pd-Pd shells. To obtain more detailed structural information, a theoretical model of tetragonal PdO was used to
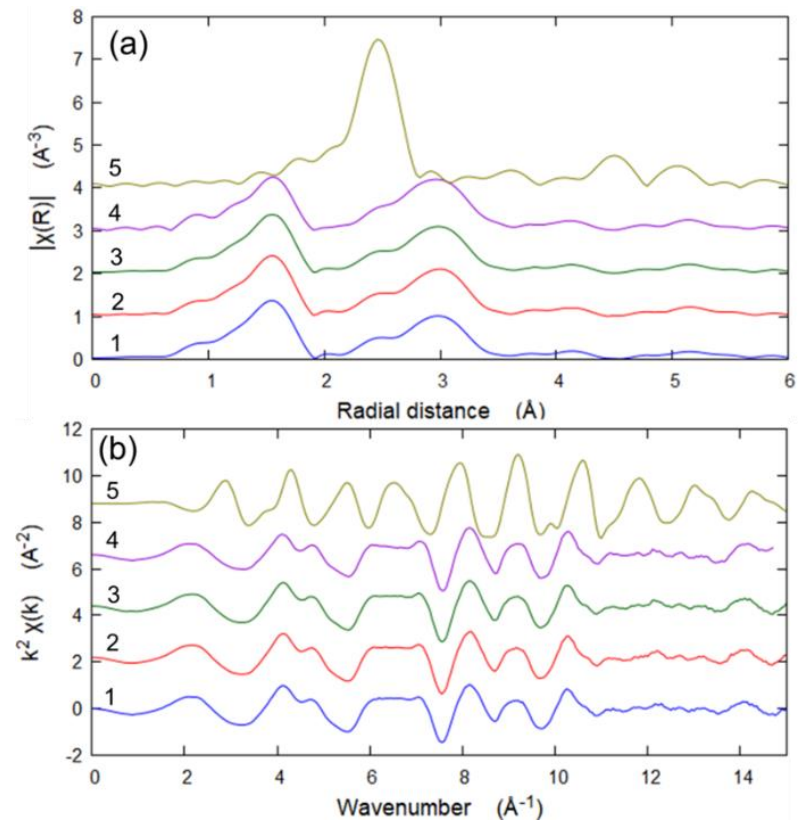

Figure 10. $\mathrm{k}^{3}$-weighted Pd K-edge EXAFS spectra for the three catalysts and PdO, $\mathrm{Pd}$ metal references; (a) R-space; (b) k-space. 1-3: Pd,Pt, $\mathrm{TiO}_{2} / \mathrm{H}-\mathrm{ZSM}-5$ (23, 50, 80); 4: PdO; 5: Pd metal. 
fit the experimental data. The PdO reference was analysed first to verify the reliability of the model, of which the best-fit parameters and the fit in R-space are shown in Table S1 and Figure S7 of ESI 5, respectively. The data shown in Table S1, specifically the coordination numbers (CNs) of the two Pd-Pd shells, indicates similar PdO particle size in the three catalysts. This supports the conclusions drawn from the XRD and TEM analysis, and suggests that broadly speaking, there are no major differences in $\mathrm{Pd}$ composition and physical characteristics between the samples. The relatively large value of $\mathrm{CNs}$ of $\mathrm{Pd}-\mathrm{Pd}$ shells obtained from the catalysts suggests that $\mathrm{PdO}$ presents dominantly as aggregates/nanoparticles. The theoretical ion exchange capacity between protons in $\mathrm{H}-\mathrm{ZSM}-5$ with $\mathrm{SiO}_{2}: \mathrm{Al}_{2} \mathrm{O}_{3}$ ratios of 23,50 and 80 and $\mathrm{Pd}^{2+}$ can be calculated as $6.7,3.3$ and 2.1 (in Pd wt.\%), respectively. Taking into account the actual concentrations of $\mathrm{Pd}$ of $5.3 \mathrm{wt} . \%$ in the catalysts, the fact that $\mathrm{Pd}$ exists mostly as aggregates/NPs, even with H-ZSM-5 (23) as support, suggests that either the palladium precursor molecules could not diffuse inside ZSM-5 pores or that ion exchanged $\mathrm{Pd}$ species sintered upon heat treatment and formed $\mathrm{PdO}$ aggregates. In addition, the coordination number and bond distance of the $\mathrm{Pd}-\mathrm{O}$ shell determined by the curve-fitting analysis were independent of the $\mathrm{SiO}_{2}: \mathrm{Al}_{2} \mathrm{O}_{3}$ ratio of $\mathrm{H}-\mathrm{ZSM}-5$ and are similar to those of bulk PdO. This confirms the observations made in the XANES that the local structure of dispersed PdO is similar to that of bulk PdO.

EXAFS spectra measured at the platinum edge of the three catalysts, $\mathrm{PtO}_{2}$ and $\mathrm{Pt}$ foil references are shown Figure 11 .

The spectra of the three catalysts show a closer resemblance to that of the $\mathrm{PtO}_{2}$ reference compared to that of $\mathrm{Pt}$ foil, which suggests the oxide nature of $\mathrm{Pt}$ in those samples. However, there are a few differences between the spectra of the catalysts and that of the $\mathrm{PtO}_{2}$ reference (Figure 11a). This is likely because
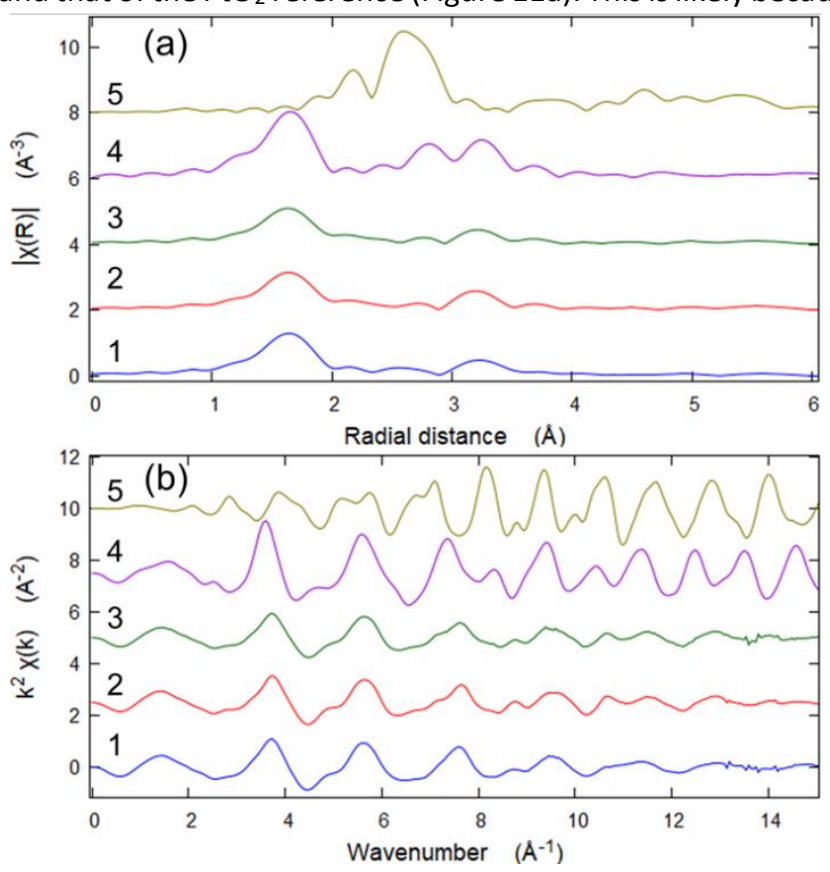

Figure 11. $\mathrm{k}^{3}$-weighted $\mathrm{Pt} \mathrm{L}_{111}$-edge EXAFS spectra for the three catalysts and $\mathrm{PtO}_{2}$,

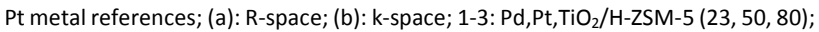
4: $\mathrm{PtO}_{2} ;$ 5: Pt metal.
$\mathrm{Pt}$ is present in the catalyst as $\mathrm{PtO}_{\mathrm{x}}$ with $\mathrm{x}<2$, consistent with the XANES result (Figure 9).

The theoretical model of tetragonal PtO was also used to fit the experimental data from $\mathrm{Pd}, \mathrm{Pt}, \mathrm{TiO}_{2} / \mathrm{H}-\mathrm{ZSM}-5$ (23) (Figure $\mathrm{S} 8$ ) as $\mathrm{PtO}$ is the only available model of $\mathrm{PtO}_{\mathrm{x}}$ with $\mathrm{x}<2$. The best-fit parameters of such a fit are summarized in Table S2. As can be seen in Table S2, the CNs obtained with the two Pt-Pt shells are much smaller than those of the crystallographic model of PtO. This indicates a key difference compared to what was previously observed at the Pd edge and suggests that the major part of $\mathrm{Pt}$ presents as small clusters and ions. The same model was used to fit the experimental data from $\mathrm{Pd}, \mathrm{Pt}, \mathrm{TiO}_{2} / \mathrm{H}-\mathrm{ZSM}-5$ (50 and 80 ) catalysts but did not result in good fits. It can be seen in Figure 11a that the three catalysts share the two highest peaks at uncorrected distances of $1.6 \AA$ and $3.2 \AA$ although they possess minor differences in the peaks between 2 and $3 \AA$. These minor peaks likely arise because of the interaction between PtO and the $\mathrm{TiO}_{2}$ and $\mathrm{H}-\mathrm{ZSM}-5$ supports, and as such this could cause the subtle differences in speciation and location of $\mathrm{Pt}$ in the catalysts compared to the model of pure PtO. The fact that this misfit was only observed at the Pt edge might be due to the higher degree of PtO-support interaction, which is in turn is likely to be the consequence of the higher dispersion of $\mathrm{PtO}$ compared to that of $\mathrm{PdO}$.

\subsubsection{XPS}

To further study the oxidation state of $\mathrm{Pd}$ and $\mathrm{Pt}$ species of $\mathrm{Pd}, \mathrm{Pt}, \mathrm{TiO}_{2} / \mathrm{H}-\mathrm{ZSM}-5$ catalysts, X-ray photoelectron spectroscopy (XPS) was conducted as shown in Figure 12. As can be seen in Figure $12 \mathrm{a}, \mathrm{Pd}$ mostly presents as $\mathrm{Pd}^{2+}(\mathrm{PdO})$ with a binding energy of ca. $337 \mathrm{eV} .{ }^{38}$ Peak fitting also reveals peaks corresponding to $\mathrm{Pd}^{2+}$ satellites ${ }^{39}$ and to the core-level spectrum of $\mathrm{Pt} 4 \mathrm{~d}_{3 / 2}$ at ca. $331.7 \mathrm{eV} .{ }^{40} \mathrm{~A}$ minor contribution from $\mathrm{Pd}^{0}$ (metal) at a binding energy of $335 \mathrm{eV}^{41}$ was found in $\mathrm{Pd}, \mathrm{Pt}, \mathrm{TiO}_{2} / \mathrm{H}-\mathrm{ZSM}-5$ (80) (Figure 12a). Here, the ratio of the $3 \mathrm{~d}_{5 / 2}$ peak areas corresponding to $\mathrm{Pd}^{0}$ and $\mathrm{Pd}^{2+}$ were calculated to be almost 0.01, which is significantly smaller than the respective ratio shown in Table 4 (0.062). This is expected since XPS analysis is only sensitive to chemistry of the surface, where oxides are likely to dominate, while the XRD result represents an average of the whole sample. Although there is some evidence for the presence of $\mathrm{Pd}^{0}$ in the $\mathrm{Pd}, \mathrm{Pt}, \mathrm{TiO}_{2} / \mathrm{H}-\mathrm{ZSM}-5$ (50) catalyst, a reliable estimation of the amount is not possible, while it is not viable to include any contribution from metallic $\mathrm{Pd}$ to the experimental data for $\mathrm{Pd}, \mathrm{Pt}, \mathrm{TiO}_{2} / \mathrm{H}-\mathrm{ZSM}-5$ (23). Figure $12 \mathrm{~b}$ shows $\mathrm{Pt}$ to predominantly present as $\mathrm{Pt}^{2+}$ with a binding energy of approximately $72.0 \mathrm{eV}$ and with a minor contribution from $\mathrm{Pt}^{4+}$ represented by a peak at ca. $74.0 \mathrm{eV}{ }^{42}$ supporting the findings from XANES and EXAFS. Moreover, both $\mathrm{Pd} 3 \mathrm{~d}_{5 / 2}$ and $\mathrm{Pt}$ $4 f_{5 / 2}$ peaks were shown to shift to lower binding energies of $336.68 \mathrm{eV}$ from $337.18 \mathrm{eV}$ for Pd and $75.18 \mathrm{eV}$ from $75.58 \mathrm{eV}$ for $\mathrm{Pt}$ as the $\mathrm{SiO}_{2}: \mathrm{Al}_{2} \mathrm{O}_{3}$ ratio increased from 23 to 80 (Table S3 in ESI 6). This indicates a decrease in electron deficiency of Pd and $\mathrm{Pt}$ on the less acidic supports, which agrees well with literature. ${ }^{43}, 44$ These findings support the results from XRD analysis, specifically the bimetallic/PdO ratio listed in 

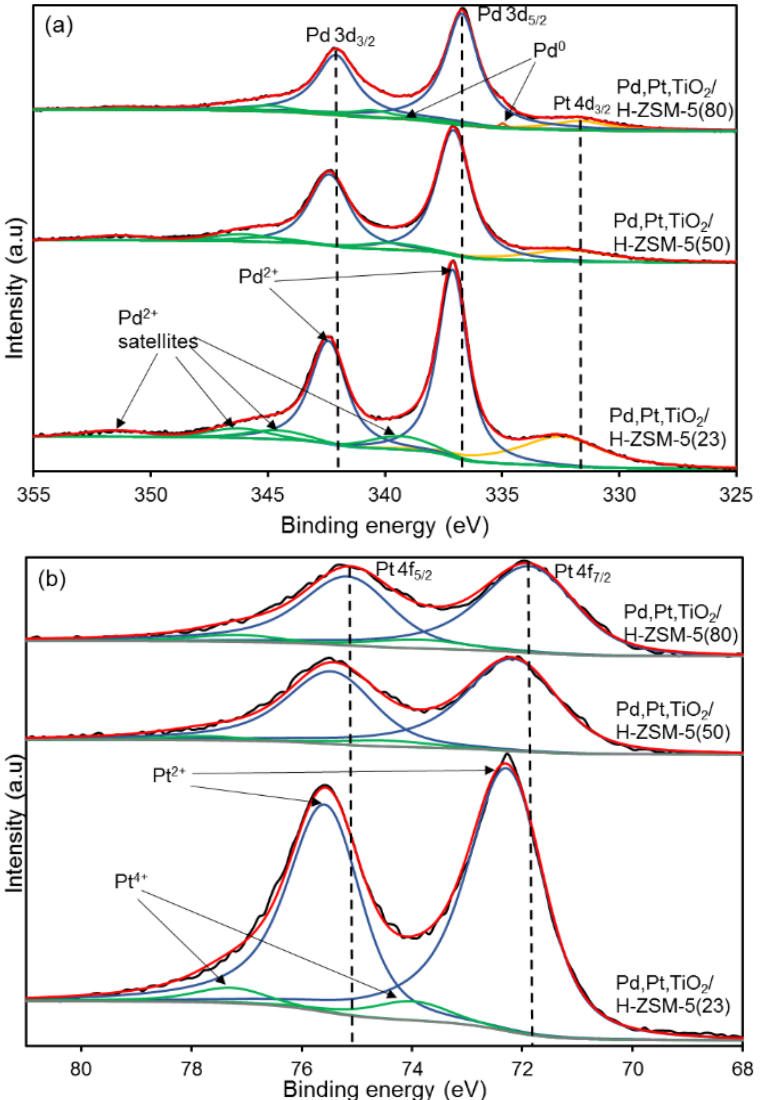

Figure 12. XPS spectra of $\mathrm{Pd}, \mathrm{Pt}, \mathrm{TiO}_{2} / \mathrm{H}-\mathrm{ZSM}-5$ catalysts in (a) Pd $3 d$ and (b) Pt $4 \mathrm{f}$ regions. Colour codes: signal (black), fit (red), background (grey), $\mathrm{Pd}^{2+}$ (blue), $\mathrm{Pd}^{2+}$ satellites (green), $\mathrm{Pd}^{0}$ (orange), $\mathrm{Pt}_{4 \mathrm{~d}_{3 / 2}}$ (yellow), $\mathrm{Pt}^{2+}$ (blue), $\mathrm{Pt}^{4+}$ (green).

Table 4, which indicates the higher quantity of metallic species being present in the ZSM- 5 supported catalysts of higher $\mathrm{SiO}_{2}: \mathrm{Al}_{2} \mathrm{O}_{3}$ ratios. Interestingly, $\mathrm{Pd}, \mathrm{Pt}, \mathrm{TiO}_{2} / \mathrm{H}-\mathrm{ZSM}-5$ (80 and 50 ) are also the more active catalysts compared to the $\mathrm{Pd}, \mathrm{Pt}, \mathrm{TiO}_{2} / \mathrm{H}-\mathrm{ZSM}-5$ (30 and 23 ) catalysts (Table 1 ) suggesting the importance of a lower oxidation state or facile redox behaviour for higher activity. Khudorozhkov et al. also used insitu XPS to show the presence of $\mathrm{Pd}^{2+}$ and $\mathrm{Pd}(0)$ on working $\mathrm{Pd} / \mathrm{Al}_{2} \mathrm{O}_{3}$ catalysts for propane oxidation. ${ }^{45}$

\subsubsection{TPR}

TPR profiles of the catalysts supported on $\mathrm{H}-\mathrm{ZSM}-5$ materials of different $\mathrm{SiO}_{2}: \mathrm{Al}_{2} \mathrm{O}_{3}$ ratios are shown in Figure 13 .

Figure 13a shows that relatively sharp peaks with high intensity were observed at $-5.8,-3.9,-8.7$ and $-3.5{ }^{\circ} \mathrm{C}$ for the catalysts corresponding to $\mathrm{SiO}_{2}: \mathrm{Al}_{2} \mathrm{O}_{3}$ ratios of $23,30,50$, and 80 , respectively; which can be attributed to the reduction of $\mathrm{Pd}$ or Pt oxides to the corresponding metals. ${ }^{46-48}$ Although there is no correlation between the reduction temperature of the oxides and the $\mathrm{SiO}_{2}: \mathrm{Al}_{2} \mathrm{O}_{3}$ ratio of the support, the area under the peaks is shown to decrease from 18.3, 17.5, 14.2 to 10.8 (in arbitrary area units calculated per gram of sample) with the increase in the $\mathrm{SiO}_{2}: \mathrm{Al}_{2} \mathrm{O}_{3}$ from $23,30,50$ to 80 respectively. This suggests either there is less oxide or the average oxidation state is lower in the catalysts with higher $\mathrm{SiO}_{2}: \mathrm{Al}_{2} \mathrm{O}_{3}$ ratios. Figure $13 \mathrm{~b}$ is the enlarged version of the profile of the $\mathrm{Pd}, \mathrm{Pt}, \mathrm{TiO}_{2} / \mathrm{H}-\mathrm{ZSM}-5$
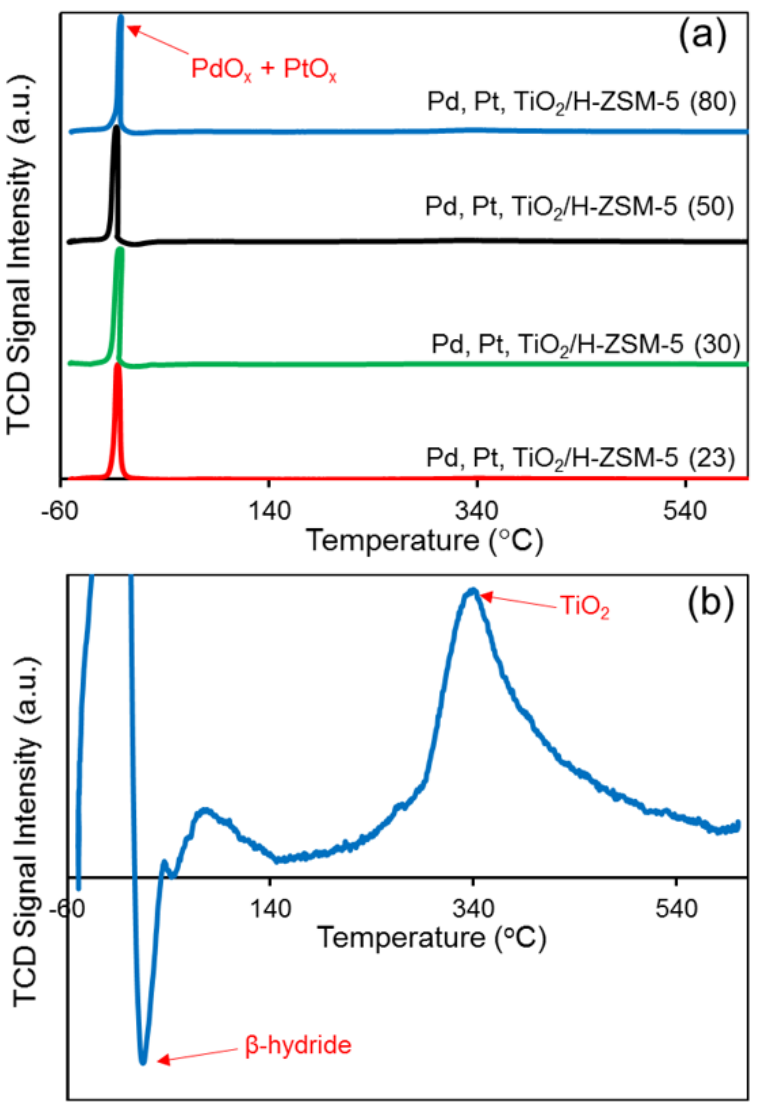

Figure 13. $\mathrm{H}_{2}$-TPR profiles of (a) the four catalysts with different $\mathrm{SiO}_{2}: \mathrm{Al}_{2} \mathrm{O}_{3}$ ratios in the support and (b) enlarged versions of the profile of $\mathrm{Pd}, \mathrm{Pt}, \mathrm{TiO}_{2} / \mathrm{H}-\mathrm{ZSM}-5(80)$ to show the peaks corresponding to the presence of $\beta$-hydride and $\mathrm{TiO}_{2}$ reduction.

(80) catalyst shown in Figure 13a. The negative peak, observed ca. $14{ }^{\circ} \mathrm{C}$ in the profiles of Pd,Pt, $\mathrm{TiO}_{2} / \mathrm{H}-\mathrm{ZSM}-5(30,50,80)$ and around $44{ }^{\circ} \mathrm{C}$ in that of $\mathrm{Pd}, \mathrm{Pt}, \mathrm{TiO}_{2} / \mathrm{H}-\mathrm{ZSM}-5$ (23), shows the release of $\mathrm{H}_{2}$ and can be attributed to the decomposition of a $\beta$ hydride species of $\mathrm{Pd}$ (or $\mathrm{Pt}$ ). ${ }^{49}$ The intensity of this peak for $\mathrm{Pd}, \mathrm{Pt}, \mathrm{TiO}_{2} / \mathrm{H}-\mathrm{ZSM}-5(30,50,80)$ is significantly higher than that of $\mathrm{Pd}, \mathrm{Pt}, \mathrm{TiO}_{2} / \mathrm{H}-\mathrm{ZSM}-5$ (23), implying a larger quantity of the $\beta$ hydride species present. The second peak, observed between 240-540 ${ }^{\circ} \mathrm{C}$, is quite broad and can be assigned to the reduction of $\mathrm{TiO}_{2} \cdot 19$ The lower oxidation state of $\mathrm{Pd}$, as signified by the decrease in peak area for $\mathrm{PdO}$ reduction and increase in peak area for decomposition of the $\beta$-hydride species, on zeolites with higher $\mathrm{SiO}_{2}: \mathrm{Al}_{2} \mathrm{O}_{3}$ ratios suggests the possibility of an easier exchange between or co-existence of $\mathrm{PdO}$ and $\mathrm{Pd}(0)$ under reaction conditions for the more active catalysts. The suggestion of a positive effect of the presence of a metallic species or oxides with low oxidation states on catalyst activity is consistent with that found from XRD (Table 4) and XPS analyses (Figure 12a).

\subsection{Catalyst stability}

The stability of catalysts prepared using different supports was compared and illustrated in Figure 14. The catalyst prepared on H-ZSM-5 (23) was found to be the most stable while the other two lost around $13 \%$ (relatively) of their corresponding activities 
over $35 \mathrm{~h}$ on stream at $300^{\circ} \mathrm{C}$. The better stability of the catalyst supported on H-ZSM-5 (23), may be explained by its higher

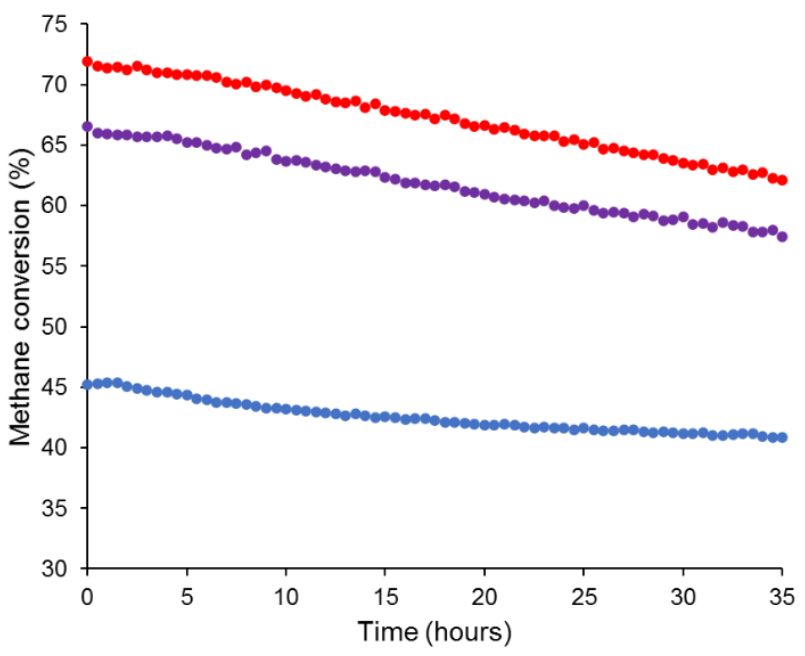

Figure 14. Comparison of the stability of catalysts prepared on different supports for

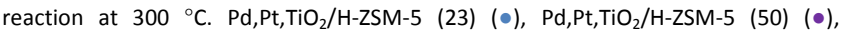
$\mathrm{Pd}, \mathrm{Pt}, \mathrm{TiO}_{2} / \mathrm{H}-\mathrm{ZSM}-5$ (80) (•).

acidity, Table 3, which has been reported to increase the stability of the PdOx species on the surface. ${ }^{15}$

To further understand the mechanism of deactivation, the $\mathrm{Pd}, \mathrm{Pt}, \mathrm{TiO}_{2} / \mathrm{H}-\mathrm{ZSM}-5$ (80) catalyst that had been run for $50 \mathrm{~h}$ was recovered and analysed using XRD, BET, TGA- $\mathrm{O}_{2}$ and STEM. XRD analyses, shown in Figure S9 in ESI 7, confirmed that the crystal structure of this sample remained intact after $50 \mathrm{~h}$ of reaction at $300{ }^{\circ} \mathrm{C}$. Furthermore, BET analysis reveals that the surface area and micropore volume of $\mathrm{Pd}, \mathrm{Pt}, \mathrm{TiO}_{2} / \mathrm{H}-\mathrm{ZSM}-5$ (80), before and after reaction, are almost identical (entries 9 and 10 in Table 2). TGA analyses of the two samples in $\mathrm{O}_{2}$ was carried out and the result is illustrated in Figure S10 in ESI 7. It can be seen that by heating the two samples in $\mathrm{O}_{2}$ flow from 50 to $800{ }^{\circ} \mathrm{C}$ the original and aged catalysts have lost approximately 5 and 3 $\%$ of their original weight, respectively. However, most of the above weight loss occurred around $100{ }^{\circ} \mathrm{C}$ and can be attributed to the desorption of the physisorbed water (moisture) in these samples. Thus, no sign of coke formation was observed here. Original and aged samples were also analysed by HAADF and STEM-EDS and an important difference was observed between the two samples. It can be seen in Figures S11 (b and c), Pd and Pt are finely dispersed and well mixed in the original sample. Whereas, a significant degree of aggregation has occurred in the deactivated sample as can be seen in Figures $\mathrm{S} 11$ (e and f) However, it is interesting to observe that $\mathrm{Pd}$ and $\mathrm{Pt}$ signals were still found in the same location before and after the course of aggregation, suggesting the presence of bimetallic species. XRD data shown in Figure S9 revealed that the average crystallite size of PdO has increased from $7.6 \mathrm{~nm}$ in the original catalyst to $10.4 \mathrm{~nm}$ in the aged one, which further confirms the aggregation shown in STEM analysis. The aggregation shown here might be one of the reasons for the catalyst deactivation. However, the ratio between the areas under the bimetallic peak at $40^{\circ}$ and the $\mathrm{PdO}(101)$ peak at $34^{\circ}$ of the aged sample was calculated to be 0.048 compared to that of 0.062 in the fresh catalyst, which suggests less bimetallic species relative to oxide present in the aged sample. As highlighted in Figure 5, this decrease in the content of bimetallic species content might also contribute to the observed catalyst deactivation.

The activity of the $\mathrm{Pd}, \mathrm{Pt}, \mathrm{TiO}_{2} / \mathrm{ZSM}-5$ (80) catalyst was determined in the presence of $9 \mathrm{~mL} \mathrm{~min}-1$ water in the reaction stream. The activity was observed to decrease slightly in the presence of water with the $\mathrm{T}_{50 \%}$ increasing from $290{ }^{\circ} \mathrm{C}$ to 328 ${ }^{\circ} \mathrm{C}$ under dry conditions and in the presence of water respectively, Figure S12 in ESI 8. However, the stability of the catalyst was not significantly affected by the presence of water in the feed. Figure $\mathrm{S} 13$ shows the stability of $\mathrm{Pd}, \mathrm{Pt}, \mathrm{TiO}_{2} / \mathrm{ZSM}-5$ (80) under dry conditions at $300^{\circ} \mathrm{C}$ and in the presence of water at $350{ }^{\circ} \mathrm{C}$ and the decrease in conversion as shown by the gradient of the graphs does not change with the addition of water. To determine whether the deactivation observed in the presence of water was permanent, after Pd,Pt, TiO $2 / \mathrm{ZSM}-5$ (80) had been run for 43 hours with $9 \mathrm{~mL} \mathrm{~min}^{-1}$ water in the feed, the feed was transferred to pass directly over the catalyst rather than through the water saturator and the initial activity in the absence of water was again observed, Figure S14. Under these conditions the catalyst showed good stability with the conversion decreasing from $94.4 \%$ to $90.4 \%$ over 20 hours.

\subsection{Is Pd-Pt bimetallic the important protagonist for methane combustion?}

To confirm whether or not the Pd-Pt bimetallic species are responsible for the increase in catalytic activity obtained with less acidic supports, a sample in which bimetallic species formation was promoted using a hydrogen pre-treatment step was prepared as described in section 2.2.

The catalytic activity for such a sample was compared with the fresh $\mathrm{Pd}, \mathrm{Pt}, \mathrm{TiO}_{2} / \mathrm{H}-\mathrm{ZSM}-5$ (80) catalyst. Included in the comparison are two other catalysts, one in which $2 \% \mathrm{Pt}$ was replaced by $2 \%$ of Pd leading to a total Pd loading of $7 \mathrm{wt} . \%$ and the other where Pd was deposited first followed by calcination, and then by the deposition of $\mathrm{Pt}$ and finally by another calcination. The activity profiles of the 4 samples are illustrated in Figure 15 and the summary of XRD is given in Table 5.

The fact that the catalyst in which Pd, Pt were deposited in two consequent steps and the sample with $7 \% \mathrm{Pd}$ are significantly less active compared to the standard and the $\mathrm{H}_{2}$-pretreated

Table 5. Summary of XRD data

\begin{tabular}{|c|c|c|c|c|}
\hline \multirow{2}{*}{ Catalyst } & \multicolumn{3}{|c|}{$\begin{array}{l}\text { Average crystallite size } \\
\qquad(\mathrm{nm})^{*}\end{array}$} & \multirow{2}{*}{$\begin{array}{c}\text { Bimetallic } \\
\text { /PdO } \\
\text { peak area } \\
\text { ratio** }\end{array}$} \\
\hline & $\mathrm{PdO}$ & $\mathrm{TiO}_{2}$ & Bimetallic & \\
\hline $\begin{array}{c}\mathrm{H}_{2} \text {-treated } \mathrm{Pd}, \mathrm{Pt}, \mathrm{TiO}_{2} / \mathrm{HZSM}-5 \\
\text { (80) }\end{array}$ & 11.9 & 11.3 & 31.3 & 0.32 \\
\hline Aged Pd,Pt, $\mathrm{TiO}_{2} / \mathrm{H}-\mathrm{ZSM}-5$ (80) & 10.4 & 15.7 & 40.3 & 0.048 \\
\hline $\begin{array}{c}\text { Standard Pd, } \mathrm{Pt}, \mathrm{TiO}_{2} / \mathrm{H}-\mathrm{ZSM}-5 \\
(80)\end{array}$ & 7.6 & 12.5 & 38.1 & 0.062 \\
\hline 7\%Pd, $\mathrm{TiO}_{2} / \mathrm{H}-\mathrm{ZSM}-5$ (80) & 8.5 & 13.2 & $\mathrm{np} * * *$ & - \\
\hline $\mathrm{Pd}, \mathrm{Pt}, \mathrm{TiO}_{2} / \mathrm{H}-\mathrm{ZSM}-5$ (80) 2-step & 8.3 & 13.1 & $\mathrm{np} * * *$ & - \\
\hline
\end{tabular}

** ratio of the peak area between the bimetallic peak at $40^{\circ}$ and $\mathrm{PdO}(101)$ at $\sim 34^{\circ} .^{* * *}$ no bimetallic peak observed. 


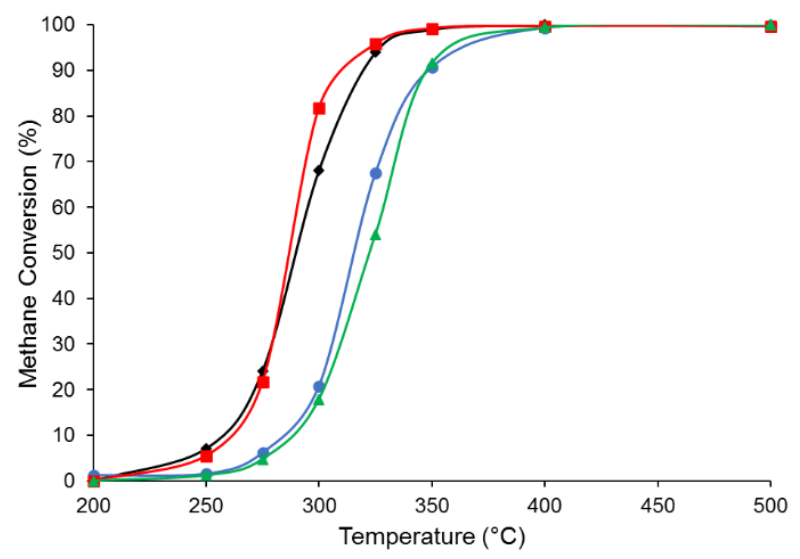

Figure 15. Catalytic activity profiles for methane oxidation over different catalysts. 7 wt.\% Pd, TiO $/$ /H-ZSM-5 (80) ( $\Delta$ ), Pd,Pt, $\mathrm{TiO}_{2} / \mathrm{H}-\mathrm{ZSM}-5$ (80) prepared in two steps (•), standard $\mathrm{Pd}, \mathrm{Pt}, \mathrm{TiO}_{2} / \mathrm{H}-\mathrm{ZSM}-5(80)(\bullet)$, and $\mathrm{Pd}, \mathrm{Pt}, \mathrm{TiO}_{2} / \mathrm{H}-\mathrm{ZSM}-5$ (80) with hydrogen pre-treatment ( $\square$ ).

catalysts suggests the simultaneous deposition of $\mathrm{Pt}$ and $\mathrm{Pd}$ during catalyst synthesis is required in an active catalyst. In addition, the absence of the bimetallic peak in the XRD (last two entries, Table 5) supports this peak being representative of a bimetallic species which is necessary for high activity. Comparing the standard and $\mathrm{H}_{2}$-treated $\mathrm{Pd}, \mathrm{Pt}, \mathrm{TiO}_{2} / \mathrm{H}-\mathrm{ZSM}-5$ (80) catalysts suggests that the size of PdO does not play an important role in the catalytic activity. Thus, the observed gradual loss of activity over time shown in Figure 14 likely results from the decrease in bimetallic/oxide ratio, specifically from 0.062 in fresh catalyst to 0.048 in the aged sample.

In summary, Figure 16 shows the ratio of the bimetallic to PdO peak areas plotted against the conversion of methane at $300^{\circ} \mathrm{C}$, for all the catalysts shown in Figure 5 and in Table 5 . It can be seen that the aged, 2-step and 7 wt.\% Pd catalysts fit well into the linear correlation previously found between the bimetallic/PdO ratio and the catalytic activity. The fact that a significant increase in this ratio, achieved with the $\mathrm{H}_{2}$-treated sample, only resulted in a small improvement in activity suggests the influence of the ratio to the activity has reached its limit.

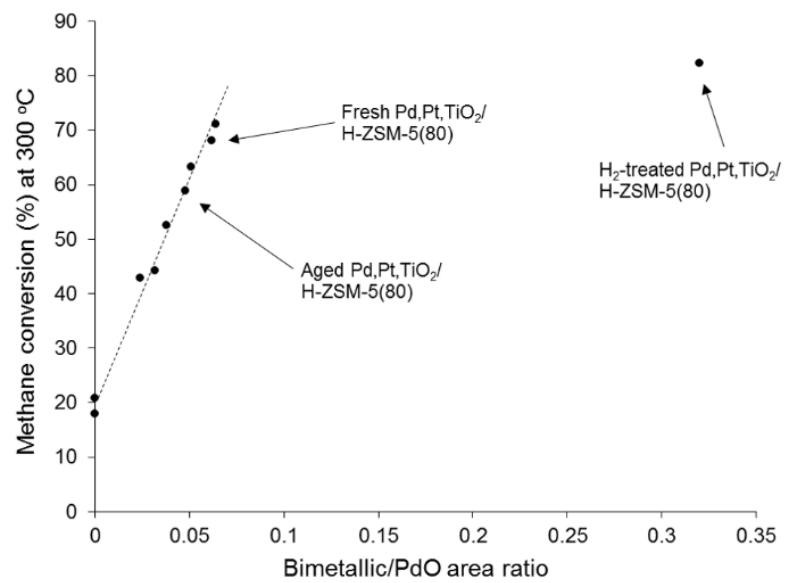

Figure 16. Correlation between the catalytic activity and the bimetallic/PdO ratio.

\section{Conclusions}

In conclusion, a series of palladium and platinum bimetallic catalysts on $\mathrm{TiO}_{2}$ and various zeolite supports ( $\mathrm{H}-\mathrm{ZSM}-5$ of different $\mathrm{SiO}_{2}: \mathrm{Al}_{2} \mathrm{O}_{3}$ ratios, $\mathrm{H}-\mathrm{MOR}$ and $\mathrm{H}-\mathrm{BEA}$ ) were synthesized using wet impregnation and tested for the combustion of methane. It is shown that, with similar $\mathrm{SiO}_{2}: \mathrm{Al}_{2} \mathrm{O}_{3}$ ratios, catalysts prepared on the $\mathrm{H}-\mathrm{ZSM}-5$ supports have lower activity compared to that of the H-MOR and H-BEA based catalysts. The catalytic activity of the $\mathrm{Pd}, \mathrm{Pt}, \mathrm{TiO}_{2} / \mathrm{H}-\mathrm{ZSM}-5$ catalysts is found to systematically increase with increase in the $\mathrm{SiO}_{2}: \mathrm{Al}_{2} \mathrm{O}_{3}$ ratio of the support. $\mathrm{NH}_{3}$-TPD reveals that, as expected, the amount of acid sites decreases with the increase in $\mathrm{SiO}_{2}: \mathrm{Al}_{2} \mathrm{O}_{3}$ ratio and suggests that the acid sites of the zeolite do not play an important role in methane activation. Characterization by $2 D$ STEM-EDS and 3D STEM-HAADF tomography shows the high dispersion of palladium and platinum and the fact that palladium and platinum were often co-located on the support. In addition, STEM-HAADF tomography revealed that in $\mathrm{Pd}, \mathrm{Pt}, \mathrm{TiO}_{2} / \mathrm{H}-\mathrm{ZSM}-5$ catalysts, most $\mathrm{Pd} / \mathrm{Pt}$ particles are located on the external surface of the $\mathrm{TiO}_{2}$ with $\mathrm{TiO}_{2}$ sitting on the external, rather than internal, surface of the zeolite, regardless of $\mathrm{SiO}_{2}: \mathrm{Al}_{2} \mathrm{O}_{3}$ ratio. $\mathrm{BET}, \mathrm{XRD}, \mathrm{ICP}-\mathrm{AES}, \mathrm{TEM}$ and XAS characterisations confirm that there is minimal difference in the content of palladium, platinum and physical characteristics between the samples supported on $\mathrm{H}-\mathrm{ZSM}-5$ of different $\mathrm{SiO}_{2}: \mathrm{Al}_{2} \mathrm{O}_{3}$ ratios. XAS analysis suggests that palladium and platinum are present mostly as the corresponding oxide nanoparticles/aggregates, which is supported by XPS and XRD analysis. However, analysis of the XRD reveals the formation of a bimetallic phase only in samples in which palladium and platinum were deposited simultaneously. The proportion of the bimetallic phase in $\mathrm{Pd}, \mathrm{Pt}, \mathrm{TiO}_{2} / \mathrm{H}-\mathrm{ZSM}-5$ catalysts is found to increase with decreasing acidity and shows linear correlation with activity. Although the precise nature of the bimetallic phase is unclear, its presence is indicative of species with metallic character and lower oxidation states. This is consistent with the XPS data which shows a shift of the PdO and PtO peaks to lower binding energy and increased metallic character with increasing $\mathrm{SiO}_{2}: \mathrm{Al}_{2} \mathrm{O}_{3}$ ratio and activity. This more facile redox behaviour is also observed in TPR analysis where a less intense $\mathrm{PdO}$ reduction peak is observed for the more active catalysts with higher $\mathrm{SiO}_{2}: \mathrm{Al}_{2} \mathrm{O}_{3}$ ratios.

Catalysts prepared on $\mathrm{H}-\mathrm{ZSM}-5$ of lower $\mathrm{SiO}_{2}: \mathrm{Al}_{2} \mathrm{O}_{3}$ ratios possess higher stability and the catalyst deactivation is mostly caused by the loss of the bimetallic species. Comparing the $\mathrm{H}_{2-}$ treated catalyst to the fresh catalyst as well as the sequentially impregnated and the $7 \mathrm{wt} . \% \mathrm{Pd}$ catalysts confirms the importance of the bimetallic species to the activity for total methane oxidation.

Thus, the formation of bimetallic species formed by the close proximity of $\mathrm{Pd} / \mathrm{Pt}$ was shown to be key in the design of highly active catalysts.

\section{Conflicts of interest}

There are no conflicts to declare. 


\section{Acknowledgements}

T.S.N acknowledges funding from EPSRC through The UK Catalysis Hub (EP/K014706/2) and beamtime from the UK Catalysis Hub BAG (run number sp15151). P.McK acknowledges funding from The Bryden Centre, The Bryden Centre project is supported by the European Union's INTERREG VA Programme, managed by the Special EU Programmes Body (SEUPB). S.J.H. and Y-C.W. acknowledge funding from the European Research Council H2020 Starter Grant EvoluTEM, EPSRC (EP/P009050/1 and the NowNano $C D T$ ), studentship funding from the China Scholarship Council and TEM instruments from the Electron Microscopy Centre at the University of Manchester.

Disclaimer: The views and opinions expressed in this paper do not necessarily reflect those of the European Commission or the Special EU Programmes Body (SEUPB).

\section{References}

1 H. Rodhe, Science, 1990, 248, 1217.

2 Z.-I. Zhou, S.-f. Ji, F.-x. Yin, Z.-x. Lu and C.-y. Li, Journal of Fuel Chemistry and Technology, 2007, 35, 583.

3 P. Gélin and M. Primet, Appl. Catal., B, 2002, 39, 1.

4 J. Chen, H. Arandiyan, X. Gao and J. Li, Catalysis Surveys from Asia, 2015, 19, 140.

5 C. Shi, L. Yang and J. Cai, Fuel, 2007, 86, 106

6 A. Kalantar Neyestanaki and L.E. Lindfors, Fuel, 1998, 77, 1727.

7 G. Ercolino, P. Stelmachowski, G. Grzybek, A. Kotarba and S. Specchia, Appl. Catal., B, 2017, 206, 712.

8 M. Cargnello, J.D. Jaén, J.H. Garrido, K. Bakhmutsky, T. Montini, J.C. Gámez, R. Gorte and P.J.S. Fornasiero, Science, 2012, 337, 713.

9 Z. Wu, J. Deng, Y. Liu, S. Xie, Y. Jiang, X. Zhao, J. Yang, H. Arandiyan, G. Guo and H. Dai, J. Catal., 2015, 332, 13.

10 Y. Lou, J. Ma, W. Hu, Q. Dai, L. Wang, W. Zhan, Y. Guo, X.-M. Cao, Y. Guo, P. Hu and G. Lu, ACS Catal., 2016, 6, 8127.

11 J.N. Carstens, S.C. Su and A.T. Bell, J. Catal., 1998, 176, 136.

12 R. Bunting, X. Cheng, J.M. Thompson and P. Hu, ACS Catal., 2019, 9, 10317.

13 O. M'Ramadj, D. Li, X. Wang, B. Zhang and G. Lu, Catal. Commun., 2007, 8, 880 .

14 H. Maeda, Y. Kinoshita, K.R. Reddy, K. Muto, S. Komai, N. Katada and M. Niwa, Appl. Catal., A, 1997, 163, 59

15 J.-H. Park, B. Kim, C.-H. Shin, G. Seo, S.H. Kim and S.B. Hong, Top. Catal., 2009, 52, 27.

16 K. Okumura, S. Matsumoto, N. Nishiaki and M. Niwa, Appl. Catal., B, 2003, 40, 151.

17 M.J. Truitt, S.S. Toporek, R. Rovira-Hernandez, K. Hatcher and J.L. White, J. Am. Chem. Soc., 2004, 126, 11144.

18 Q. Dai, Q. Zhu, Y. Lou and X. Wang, J. Catal., 2018, 357, 29.

19 A.I. Osman, J.K. Abu-Dahrieh, F. Laffir, T. Curtin, J.M. Thompson and D.W. Rooney, Appl. Catal., B, 2016, 187, 408.

20 J. Rouquerol, P. Llewellyn and F. Rouquerol, Is the BET equation applicable to microporous adsorbents?, in: P.L. Llewellyn, F. Rodriquez-Reinoso, J. Rouqerol, N. Seaton (Eds.) Studies in Surface Science and Catalysis, Elsevier 2007, pp. 4956.

21 B.D.A. Levin, Y. Jiang, E. Padgett, S. Waldon, C. Quammen, C. Harris, U. Ayachit, M. Hanwell, P. Ercius, D.A. Muller and R. Hovden, Microscopy Today, 2018, 26, 12.

22 B. Goris, W. Van den Broek, K.J. Batenburg, H. Heidari Mezerji and S. Bals, Ultramicroscopy, 2012, 113, 120.
23 M. Agote-Arán, A.B. Kroner, H.U. Islam, W.A. Sławiński, D.S. Wragg, I. Lezcano-González and A.M. Beale, ChemCatChem, 2019, 11, 473.

24 https://www.alfa.com/en/zeolites/, 2019.

25 R.Q. Long and R.T. Yang, J. Catal., 2001, 198, 20

26 L. Rodríguez-González, E. Rodríguez-Castellón, A. JiménezLópez and U. Simon, Solid State lonics, 2008, 179, 1968.

27 C.A. González, M. Bartoszek, A. Martin and C.M. de Correa Ind. Eng. Chem. Res., 2009, 48, 2826.

28 M. Watanabe, Y. Aizawa, T. lida, R. Nishimura and H. Inomata, Appl. Catal. A, 2005, 295, 150.

29 N. Ichikawa, S. Sato, R. Takahashi and T. Sodesawa, Catal. Commun., 2005, 6, 19.

30 K. Persson, A. Ersson, K. Jansson, N. Iverlund and S. Järås, J. Catal., 2005, 231, 139.

31 C.-C. Wang and J.Y. Ying, Chem. Mater., 1999, 11, 3113.

32 S. Ali Ansari, M. Mansoob Khan, M. Omaish Ansari and M. Hwan Cho, Ceram. Int., 2015, 41, 9131.

33 K. Persson, A. Ersson, S. Colussi, A. Trovarelli and S.G. Järås, Appl. Catal., B, 2006, 66, 175.

34 Y.-N. Wu, S.-J. Liao, Z.-X. Liang, L.-J. Yang and R.-F. Wang, J. Power Sources, 2009, 194, 805.

35 J.S.J. Hargreaves, Catalysis, Structure \& Reactivity, 2016, 2, 33.

36 M. Kosmulski, Adv. Colloid Interface Sci., 2018, 251, 115.

37 A. Ikhlaq and B. Kasprzyk-Hordern, Appl. Catal. B, 2017, 200, 274.

38 L.S. Kibis, A.I. Stadnichenko, S.V. Koscheev, V.I. Zaikovskii and A.I. Boronin, J. Phys. Chem. C, 2012, 116, 19342.

39 T. Pillo, R. Zimmermann, P. Steiner and S. Hüfner, Journal of Physics: Condensed Matter, 1997, 9, 3987.

40 T. Wang, R. Yang, S. Ouyang, H. Shi and S. Wang, RSC Adv., 2015, 5, 48992.

41 P. Wu, Y. Huang, L. Kang, M. Wu and Y. Wang, Sci. Rep., 2015, 5, 14173.

42 J.H. Kim, J.Y. Cheon, T.J. Shin, J.Y. Park and S.H. Joo, Carbon, 2016, 101, 449.

43 R. Harmsen, S. Bates and R. A. van Santen, Faraday Discuss., 1997, 106, 443.

44 L.L. Sheu, H. Knoezinger and W.M.H. Sachtler, J. Am. Chem. Soc., 1989, 111, 8125 .

45 A.K. Khudorozhkov, I.A. Chetyrin, A.V. Bukhtiyarov, I.P. Prosvirin and V.I. Bukhtiyarov, Top. Catal., 2017, 60, 190.

46 B. Wen, J. Jia and W.M.H. Sachtler, J. Phys. Chem. B, 2002, 106, 7520.

47 C.-B. Wang, C.-M. Ho, H.-K. Lin and H.-C. Chiu, Fuel, 2002, 81, 1883.

48 C.-P. Hwang and C.-T. Yeh, J. Mol. Catal. A: Chem., 1996, 112, 295.

49 W. Lin, Y.X. Zhu, N.Z. Wu, Y.C. Xie, I. Murwani and E. Kemnitz, Appl. Catal., B, 2004, 50, 59. 


\section{Supplementary Information}

\section{for \\ Correlation of the ratio of metallic to oxide species with activity of PdPt catalysts for methane oxidation}

Tang Son Nguyen ${ }^{\mathrm{a}, \mathrm{b} *}$, Paul McKeever ${ }^{\mathrm{a}}$, Miryam Arredondo-Arechavalac ${ }^{\mathrm{c}}$, Yi-Chi Wang ${ }^{\mathrm{d}}$, Thomas J. A. Slater ${ }^{e}$, Sarah J. Haigh ${ }^{d}$, Andrew M. Beale ${ }^{f \star}$, Jillian M. Thompson ${ }^{a \star}$

aSchool of Chemistry and Chemical Engineering, Queen's University Belfast, Belfast BT9 5AG, Northern Ireland, UK

${ }^{\mathrm{b}}$ Faculty of Biotechnology, Chemistry and Environmental Engineering, PHENIKAA University, Hanoi 10000, Vietnam

'Centre for Nanostructured Media, School of Mathematics and Physics, Queen's

University Belfast, University Road, Belfast BT7 1NN, United Kingdom

dSchool of Materials, University of Manchester, Oxford Road, Manchester M13 9PL, United Kingdom

eElectron Physical Sciences Imaging Centre, Diamond Light Source Ltd., Oxfordshire OX11 ODE, United Kingdom

'Department of Chemistry, University College London, 20 Gordon Street, London

WC1H 0AJ, U.K., \& Research Complex at Harwell, Rutherford Appleton Laboratory, Didcot OX11 OFA, U.K 


\section{ESI 1}

The BET method is, in a strict sense, not applicable in the case of microporous adsorbents $[1,2]$. However, Rouquerol et al. [3] suggested a procedure to determine an appropriate $\mathrm{p} / \mathrm{p}_{0}$ range for BET analysis of microporous materials. This procedure was utilized in this study to estimate the surface area of the ZSM-5 supports and the corresponding catalysts. Moreover, micropore volume and the concentration of $\mathrm{Pd}, \mathrm{Pt}$ in the catalysts were analyzed using the t-plot and ICP-AES methods, respectively.

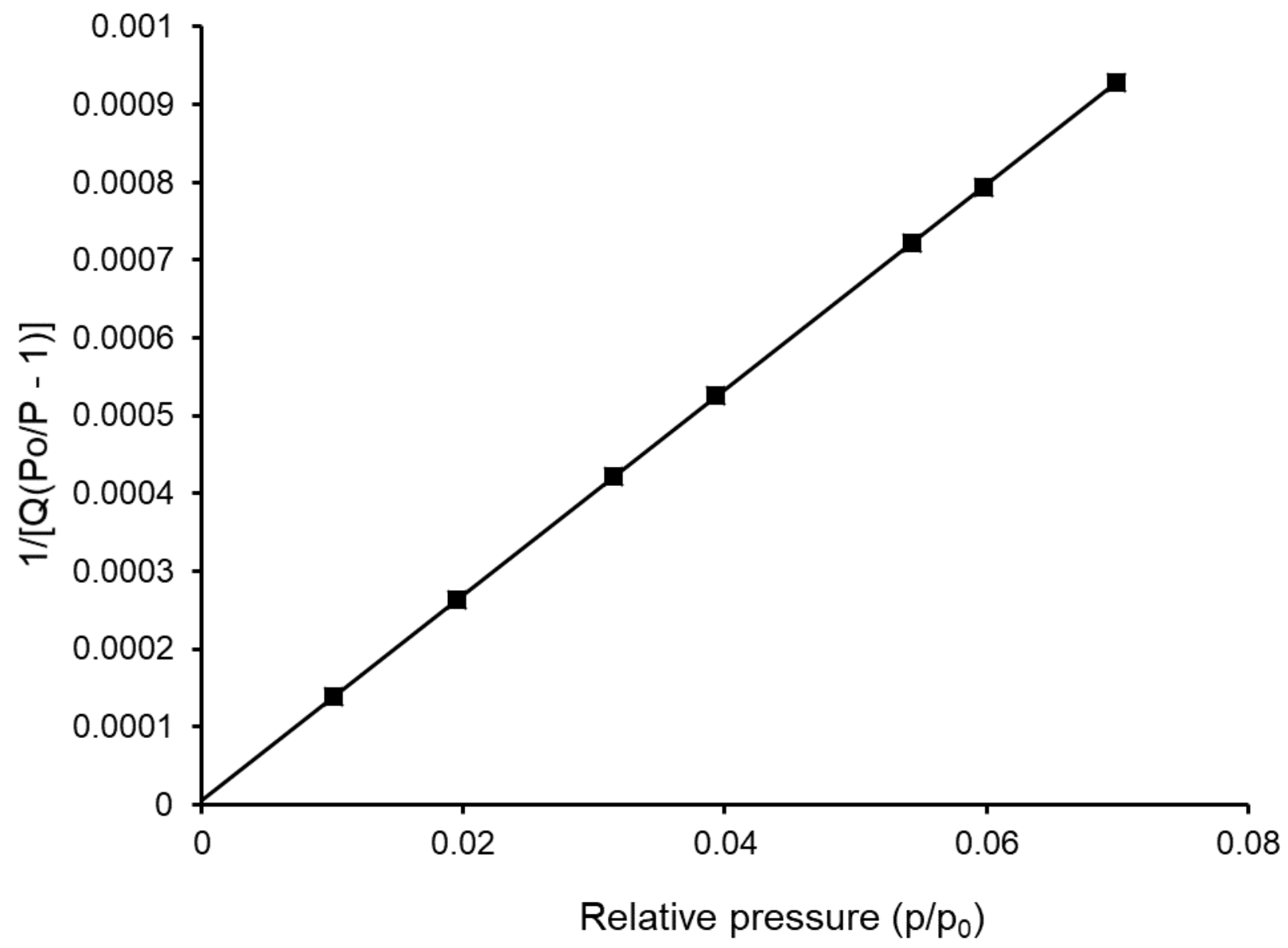

Figure S1. An example of the BET plot of the $\mathrm{Pd}, \mathrm{Pt}, \mathrm{TiO}_{2} / \mathrm{H}-\mathrm{ZSM}-5$ (80) catalyst utilizing only data in the low $\mathrm{p} / \mathrm{p}_{0}$ region (less than 0.1 ). The $\mathrm{y}$-intercept value here is 0.000006 , which is positive and thus satisfies the most important requirement proposed by Rouquerol et al. 
ESI $2 \mathrm{NH}_{3}$-TPD

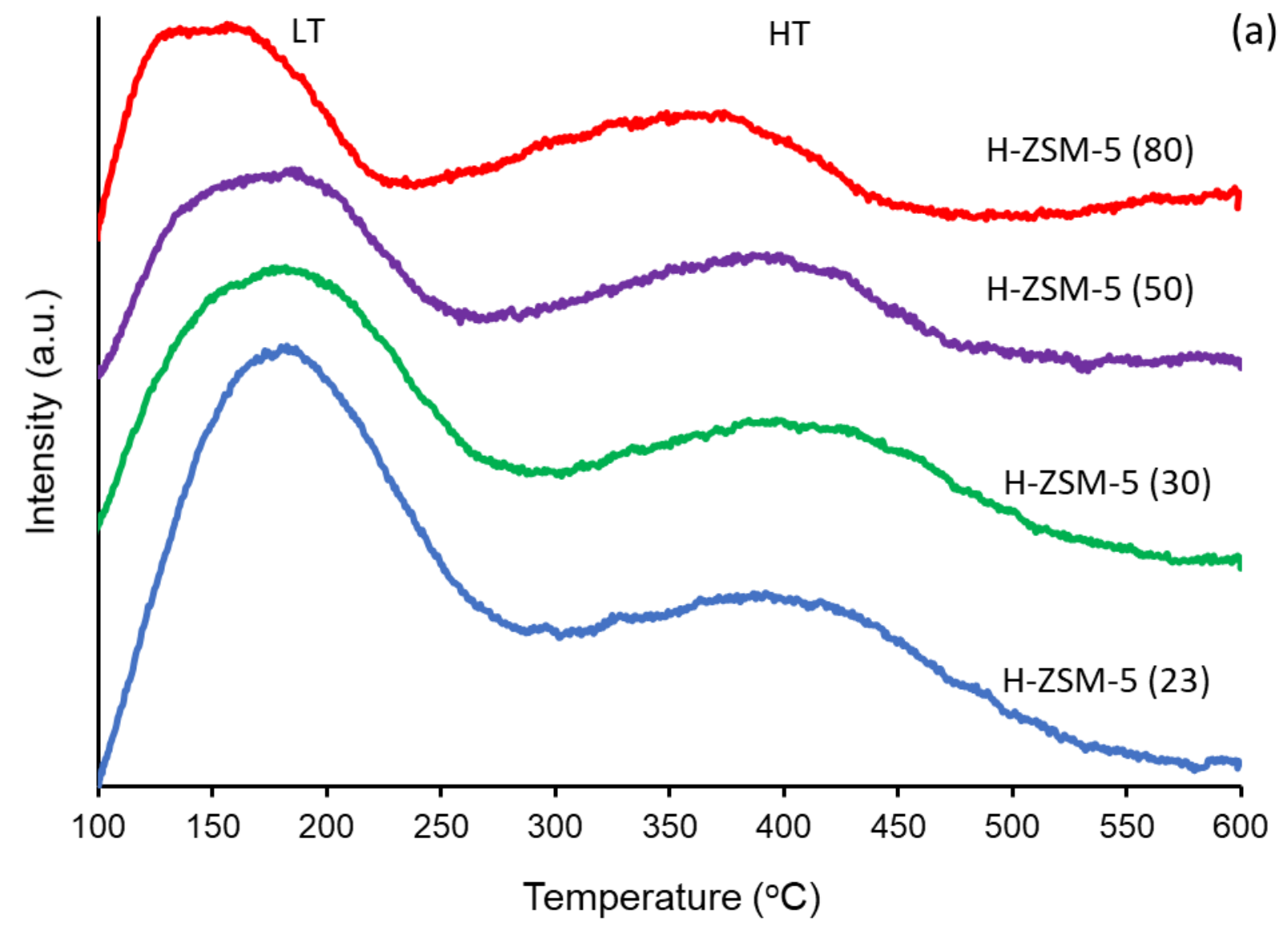




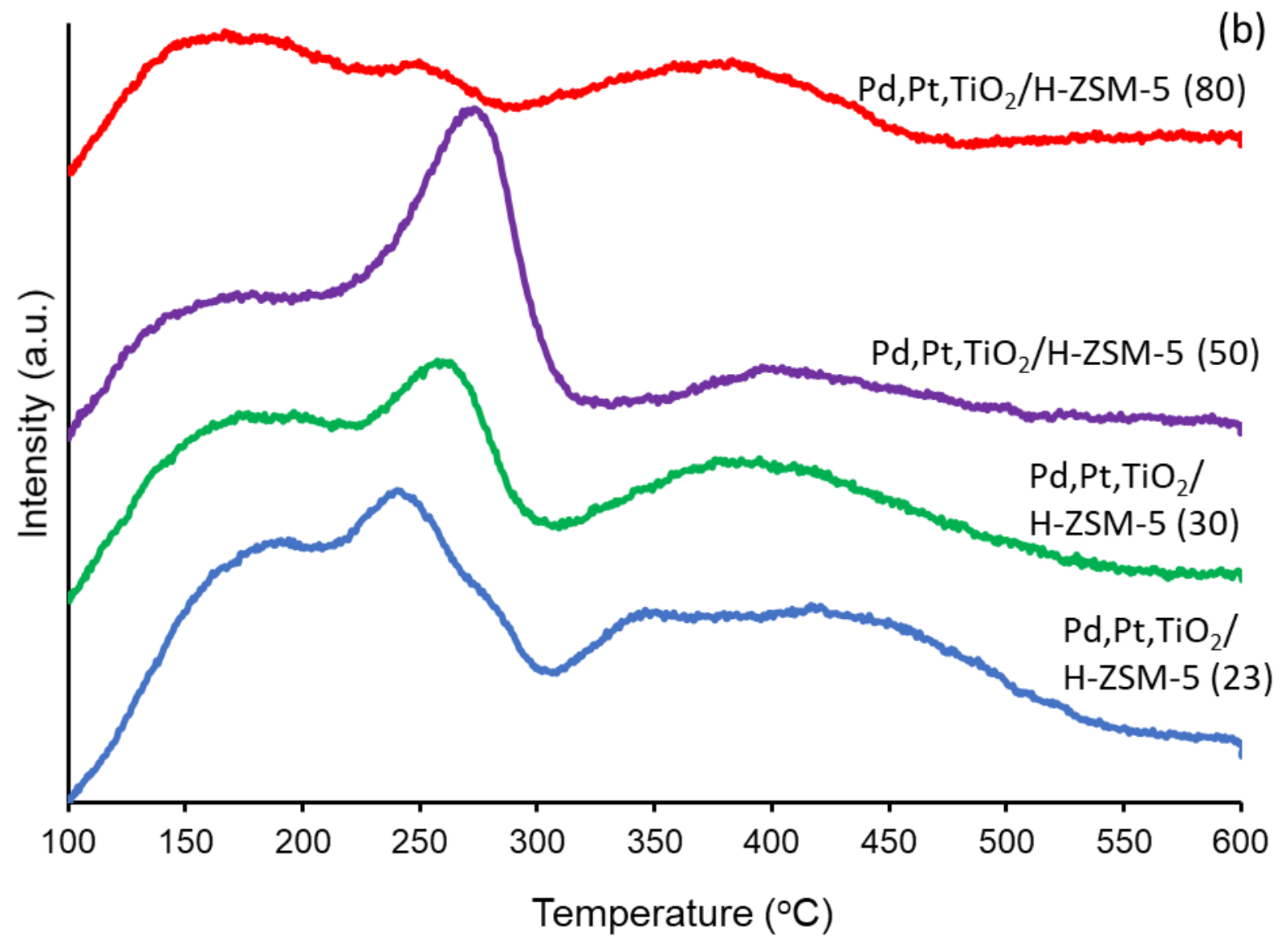

Figure S2. $\mathrm{NH}_{3}$-TPD profiles of (a) ZSM-5 supports and (b) the corresponding catalysts 


\section{ESI 3}
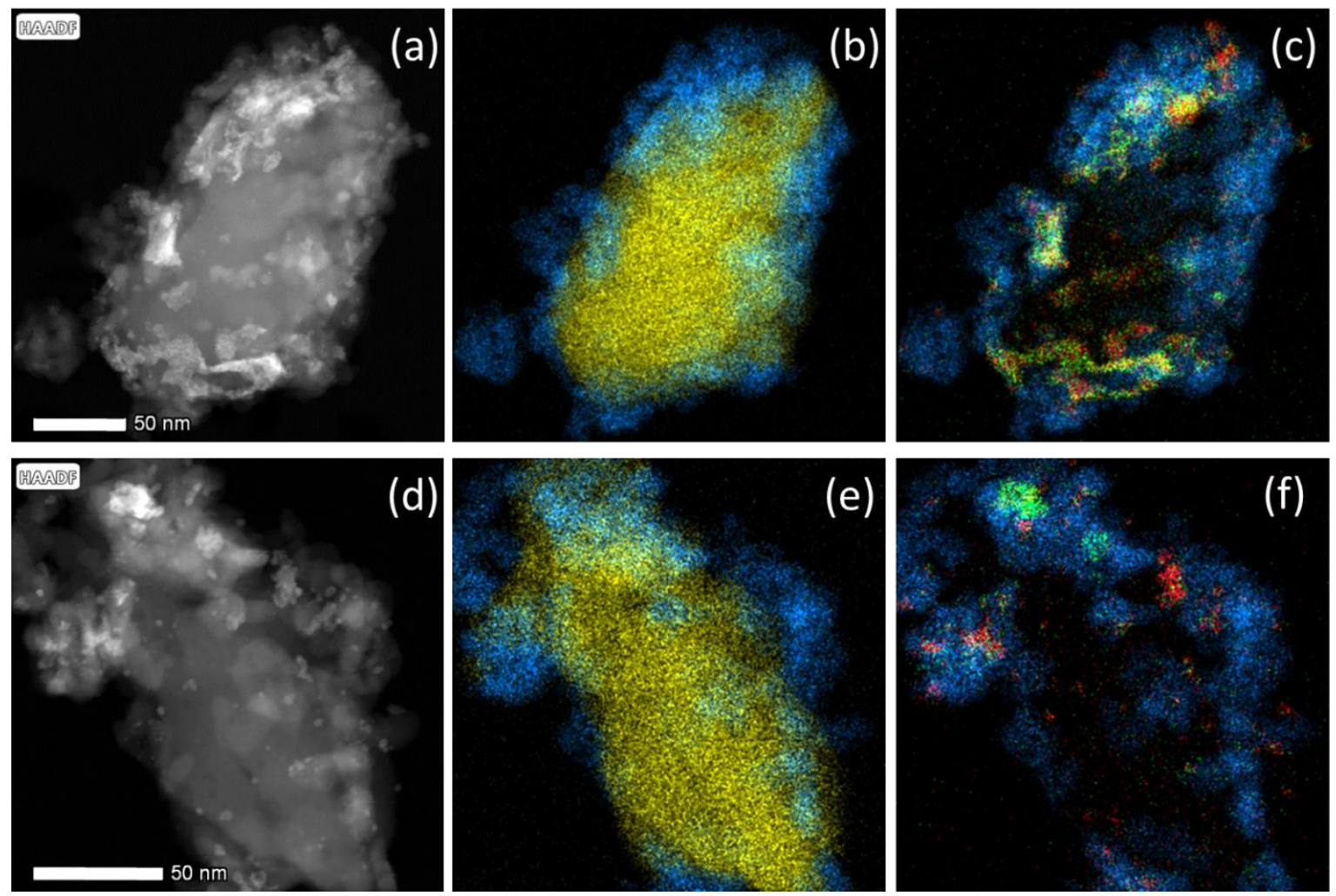

Figure S3. Scanning transmission electron microscope high angle annular dark field (STEM-HAADF) imaging (a and d) and energy dispersive X-ray spectroscopy (EDS) mapping elemental maps overlays of $\mathrm{Pd} / \mathrm{Pt} / \mathrm{TiO}_{2} / \mathrm{H}-\mathrm{ZSM}-5(23)(\mathrm{b}-\mathrm{c})$ and $\mathrm{Pd} / \mathrm{Pt} / \mathrm{TiO} / \mathrm{H}-$ ZSM-5 (80) (e - f) for Si/Ti (b and e) for Ti/Pd/Pt (c and f). The yellow indicates Si, blue Ti, red Pd and green Pt. 

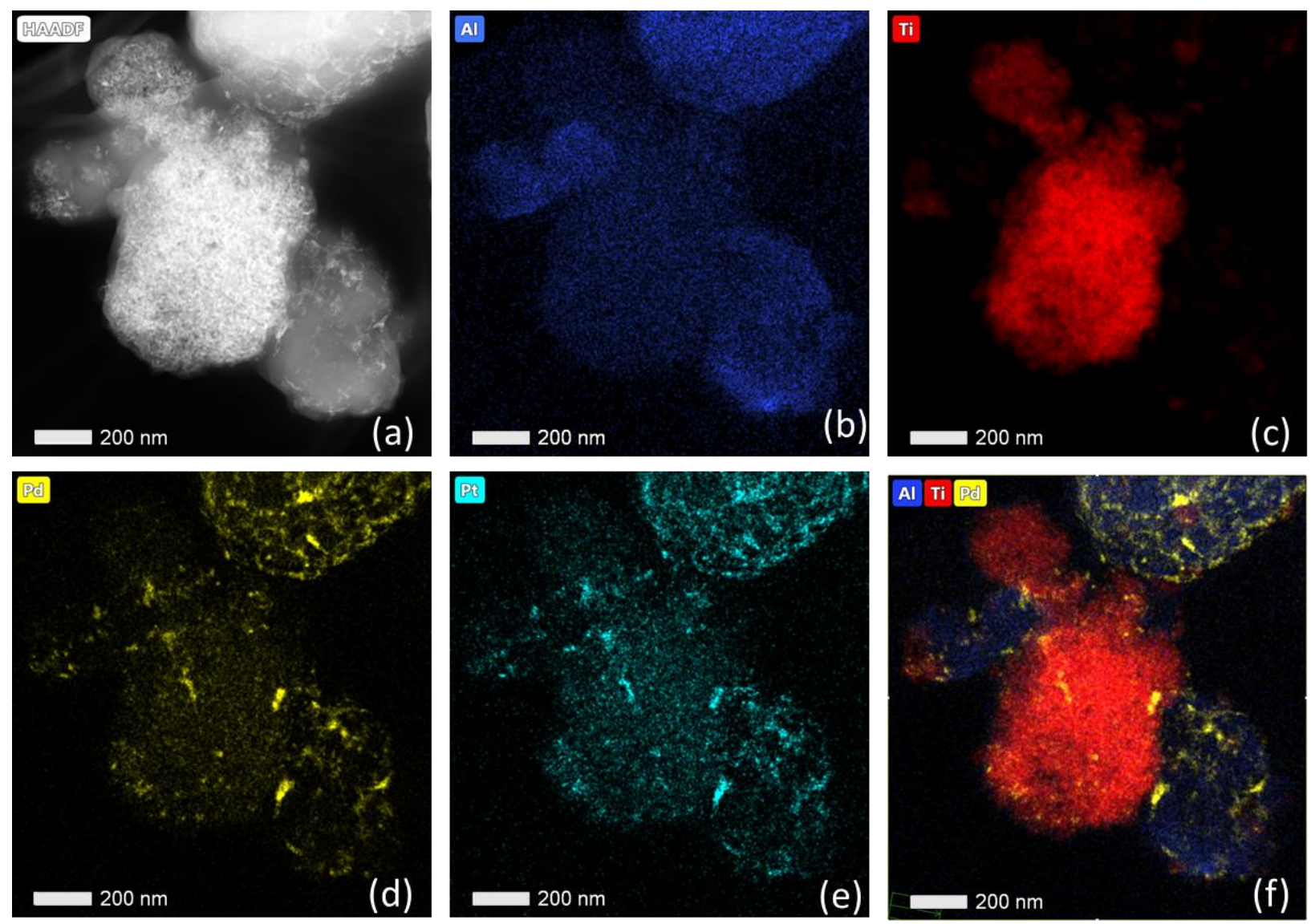

Figure S4. Scanning transmission electron microscope high angle annular dark field (STEM-HAADF) imaging (a) and energy dispersive X-ray spectroscopy (EDS) elemental maps of the $\mathrm{Pd} / \mathrm{Pt} / \mathrm{TiO}_{2} / \mathrm{H}-\mathrm{ZSM}-5$ (80) catalyst (b, c, d, e and f). The blue indicates Al, red Ti, yellow Pd and turquoise Pt. 


\section{ESI 4}
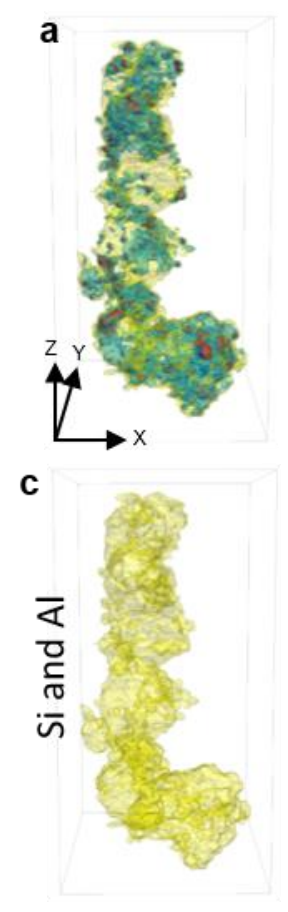

b

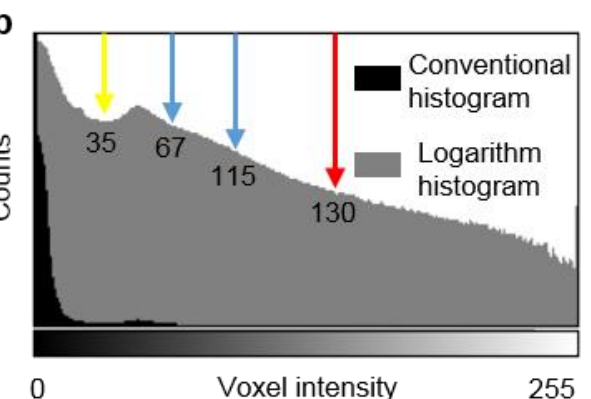

0

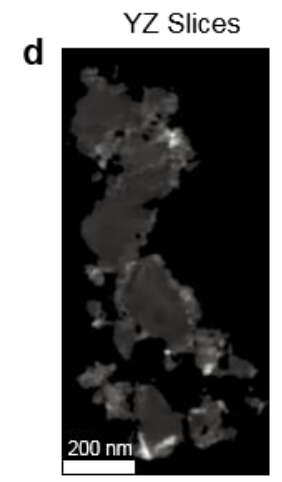

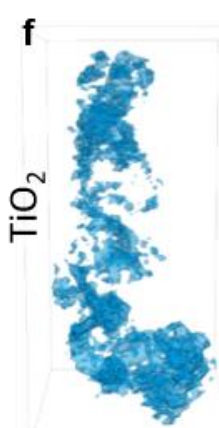

XZ Slices

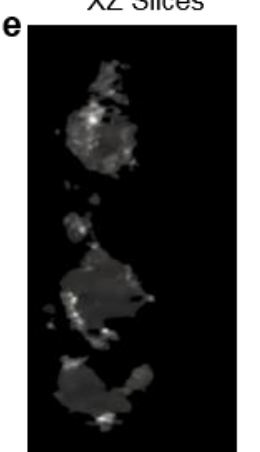

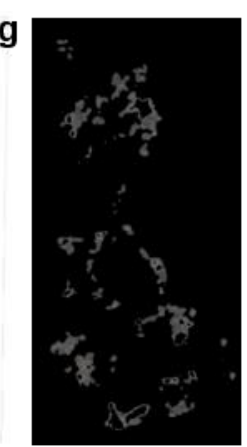
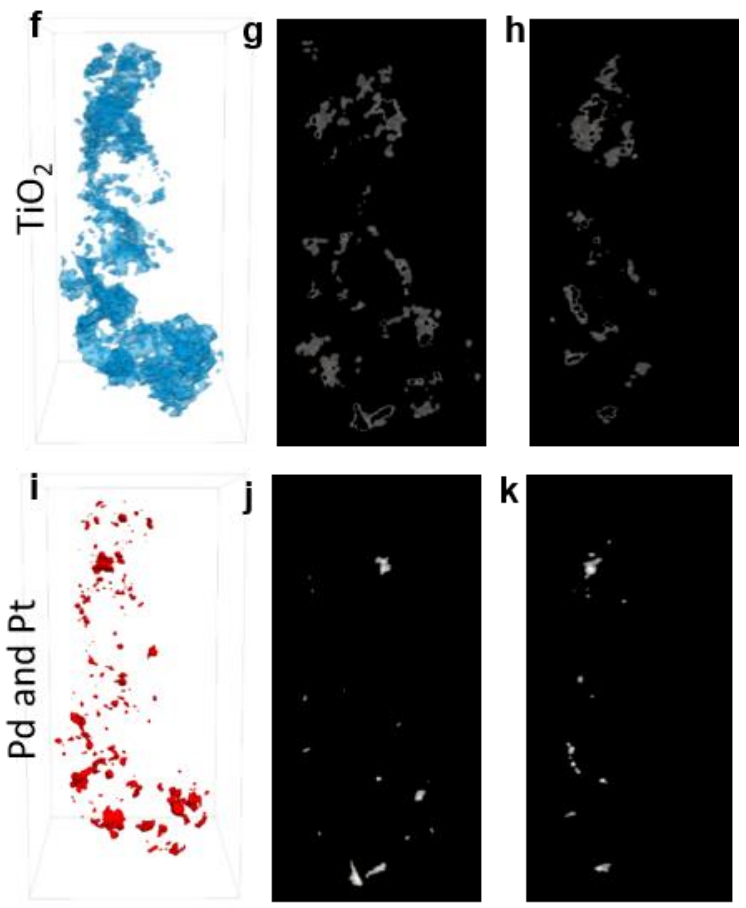

Figure S5. 3D visualisation and 2D orthoslices from a STEM-HAADF electron tomographic reconstruction of $\mathrm{Pd} / \mathrm{Pt} / \mathrm{TiO} / \mathrm{H}-\mathrm{ZSM}-5$ (23). a) 3D surface render of the reconstruction with colours to illustrate intensity differences, yellow, low HAADF intensity corresponding to Si and Al support, blue, intermediate intensity corresponding to $\mathrm{TiO}_{2}$ particles, red, high intensity as Pd and Pt rich nanoparticles. b), histogram of the unprocessed reconstruction. Voxel intensities ranging from 35-255, 67-115 and 130-255 are represented as the yellow tomogram in c) the blue tomogram in $\mathrm{f}$ ) and the red tomogram in i) respectively. d) and e), g) and h) and j) and k) are 2D slices extracted from c), f) and i), respectively. 


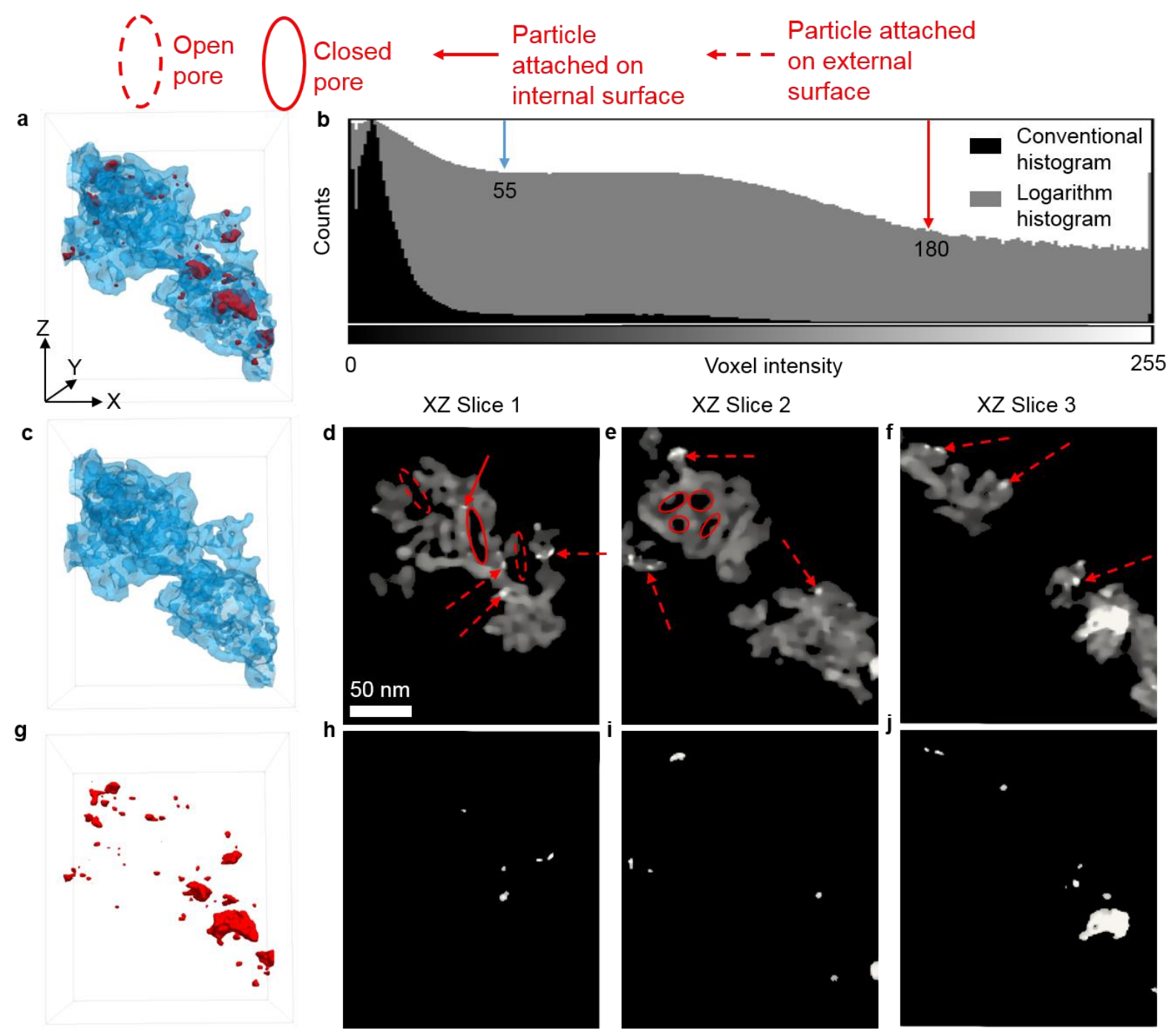

Figure S6. 3D visualisation and orthoslices from the STEM-HAADF electron tomographic reconstruction of $\mathrm{Pd} / \mathrm{Pt} / \mathrm{TiO}_{2} / \mathrm{H}-\mathrm{ZSM}-5$ (80). a) 3D surface render of the reconstruction with colours to illustrate intensity differences, blue, low HAADF STEM intensity corresponding to the $\mathrm{TiO}_{2}$ support, red, high HAADF STEM intensity corresponding to the $\mathrm{Pd}$ and $\mathrm{Pt}$ rich nanoparticles. b) histogram of the unprocessed reconstruction. Voxel intensities ranging from 55-255 and 180-255 are represented as blue tomogram in c) and red tomogram in g) respectively. $d-f$ ) and $h-j$ ) are $2 D$ slices extracted from c) and g) respectively. Legend at the top refers to the annotations on the $2 \mathrm{D}$ slices in d-f. 


\section{ESI 5}

\section{Fit at Pd K-edge}

The co-ordination numbers $(\mathrm{CNs})$ for the oxide reference were fixed as determined by its crystal structure. All other parameters, including the bond distances, and Debye-Waller factors were free to vary. Good fit was obtained for PdO, as suggested by the low R-factor. The refined bond lengths were consistent with PdO's crystal structure [4], and all the other parameters were physically sensible. Thus, the same model was used to fit the three catalysts, which results in similarly good fits.

Table S1. Best-fit parameters obtained by fitting EXAFS data measured from PdO and the three catalysts at Pd K-edge

\begin{tabular}{|c|c|c|c|c|c|c|}
\hline Sample & Shell & $\begin{array}{l}\text { Co- } \\
\text { ordination } \\
\text { number }\end{array}$ & $\begin{array}{l}\text { Bond } \\
\text { length }(\AA)\end{array}$ & $\begin{array}{l}\text { Debye- } \\
\text { Waller factor } \\
\left(\AA^{2}\right)\end{array}$ & $\begin{array}{l}\Delta \mathrm{E}_{0} \\
(\mathrm{eV})\end{array}$ & $\begin{array}{l}\text { R- } \\
\text { factor }\end{array}$ \\
\hline \multirow[t]{3}{*}{$\mathrm{PdO}$} & $1^{\text {st }}(\mathrm{Pd}-\mathrm{O})$ & 4 & 2.02 & 0.0022 & \multirow{4}{*}{-0.9} & \multirow{3}{*}{0.009} \\
\hline & $2^{\text {nd }}(P d-P d)$ & 4 & 3.03 & 0.0043 & & \\
\hline & $3^{\text {rd }}(\mathrm{Pd}-\mathrm{Pd})$ & 8 & 3.42 & 0.0049 & & \\
\hline \multirow{3}{*}{$\begin{array}{l}\mathrm{Pd}, \mathrm{Pt}, \mathrm{TiO}_{2} / \\
\mathrm{H}-\mathrm{ZSM}-5 \text { (23) }\end{array}$} & $1^{\text {st }}(\mathrm{Pd}-\mathrm{O})$ & 4.5 & 2.02 & 0.0024 & & \multirow{3}{*}{0.022} \\
\hline & $2^{\text {nd }}(P d-P d)$ & 5.0 & 3.06 & 0.0067 & \multirow[t]{2}{*}{-2.0} & \\
\hline & $3^{\text {rd }}(\mathrm{Pd}-\mathrm{Pd})$ & 6.2 & 3.45 & 0.0063 & & \\
\hline \multirow{3}{*}{$\begin{array}{l}\mathrm{Pd}, \mathrm{Pt}, \mathrm{TiO}_{2} / \\
\mathrm{H}-\mathrm{ZSM}-5 \text { (50) }\end{array}$} & $1^{\text {st }}(\mathrm{Pd}-\mathrm{O})$ & 4.5 & 2.02 & 0.0022 & \multirow{3}{*}{-2.0} & \multirow{3}{*}{0.020} \\
\hline & $2^{\text {nd }}(P d-P d)$ & 5.3 & 3.06 & 0.0066 & & \\
\hline & $3^{\text {rd }}(\mathrm{Pd}-\mathrm{Pd})$ & 6.5 & 3.45 & 0.0059 & & \\
\hline \multirow{3}{*}{$\begin{array}{l}\mathrm{Pd}, \mathrm{Pt}, \mathrm{TiO}_{2} / \\
\mathrm{H}-\mathrm{ZSM}-5 \text { (80) }\end{array}$} & $1^{\text {st }}(\mathrm{Pd}-\mathrm{O})$ & 4.4 & 2.02 & 0.0022 & \multirow{3}{*}{-1.7} & \multirow{3}{*}{0.020} \\
\hline & $2^{\text {nd }}(P d-P d)$ & 5.4 & 3.06 & 0.0065 & & \\
\hline & $3^{\text {rd }}(\mathrm{Pd}-\mathrm{Pd})$ & 6.3 & 3.45 & 0.0059 & & \\
\hline
\end{tabular}




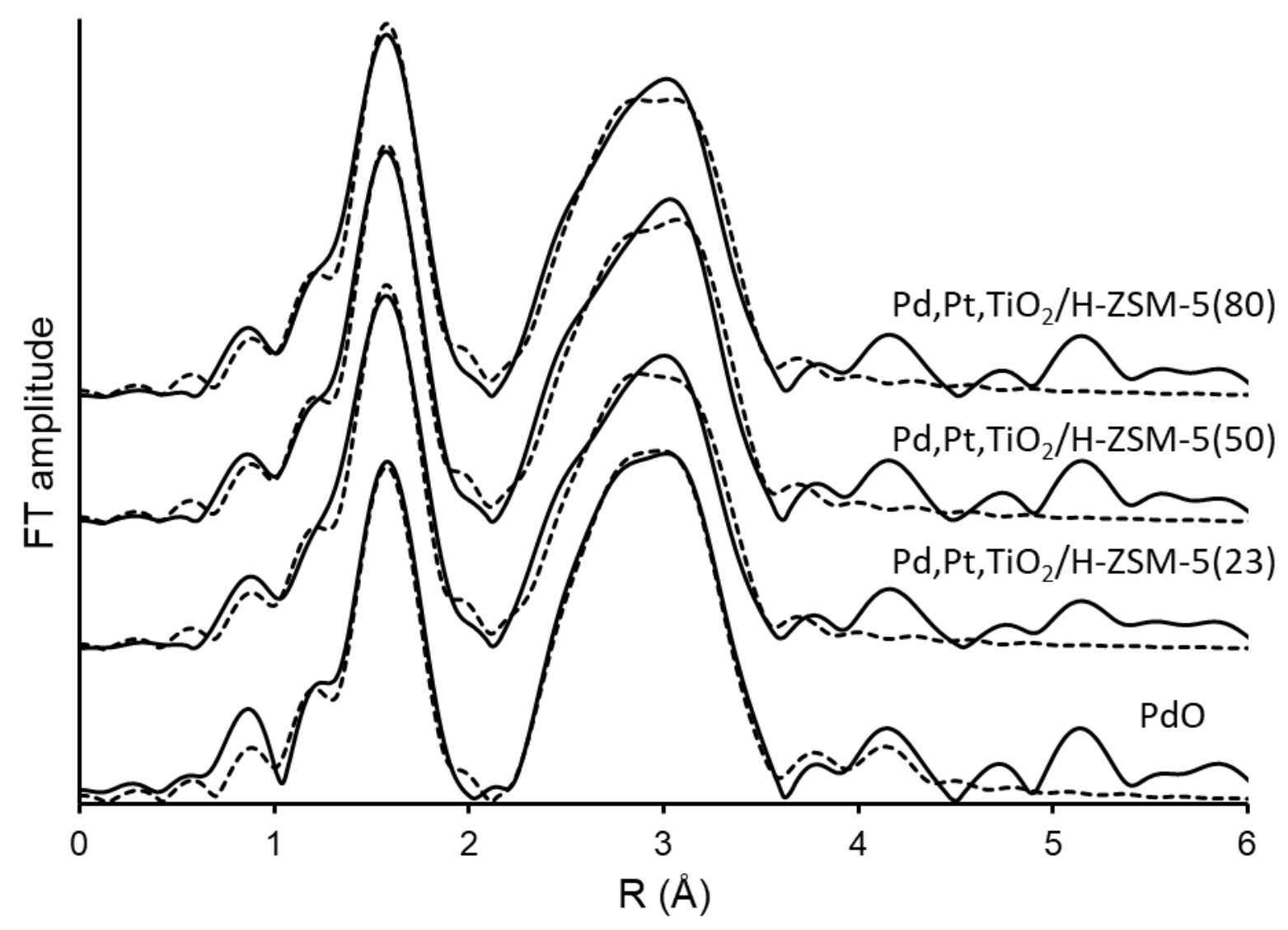

Figure S7. Experimental EXAFS data (solid line) obtained with PdO reference and the three catalysts and the corresponding fitted model from FEFF (dashed line). Data obtained at the Pd K-edge.

\section{Fit at Pt L LIII-edge}

In this fit, it was necessary to fix the Debye-Waller factor in the $3^{\text {rd }}$ and $4^{\text {th }}$ shells to 0.003 and 0.006 , respectively, as physically meaningful values could not be obtained when this parameter was free to vary. This results in a good fit with a R-factor of 0.01 . 


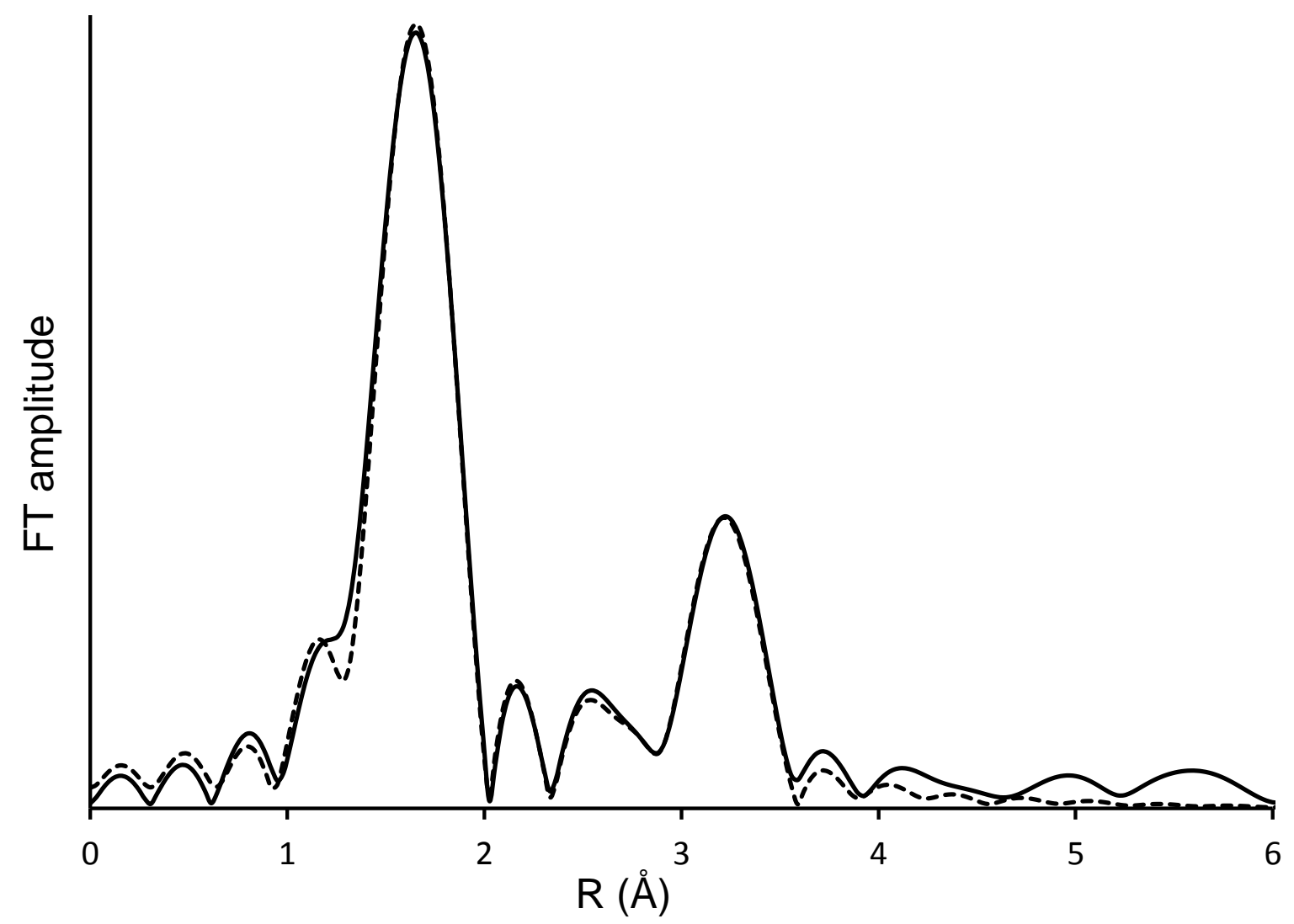

Figure S8. Experimental EXAFS data (solid line) and fitted model (dash line) for $\mathrm{Pd}, \mathrm{Pt}, \mathrm{TiO}_{2} / \mathrm{HZSM}-5$ (23). Data obtained at the Pt LוI-edge.

Table S2. Best-fit parameters obtained by fitting EXAFS data measured from $\mathrm{Pd}, \mathrm{Pt}, \mathrm{TiO}_{2} / \mathrm{H}-\mathrm{ZSM}-5$ (23) at the Pt LוI--edge.

\begin{tabular}{|c|c|c|c|c|c|c|}
\hline Sample & Shell & $\begin{array}{l}\text { Co-ordination } \\
\text { number }\end{array}$ & $\begin{array}{l}\text { Bond } \\
\text { length } \\
(\AA) \\
(\AA)\end{array}$ & $\begin{array}{l}\text { Debye- } \\
\text { Waller } \\
\text { factor }\left(\AA^{2}\right)\end{array}$ & $\begin{array}{l}\Delta \mathrm{E}_{0} \\
(\mathrm{eV})\end{array}$ & R-factor \\
\hline \multirow[t]{4}{*}{$\mathrm{PtO}^{\mathrm{a}}$} & $1^{\text {st }}(\mathrm{Pt}-\mathrm{O})$ & 4 & 2.02 & & & \\
\hline & $2^{\text {nd }}(\mathrm{Pt}-\mathrm{Pt})$ & 4 & 3.04 & & & \\
\hline & $3^{\text {rd }}(\mathrm{Pt}-\mathrm{Pt})$ & 8 & 3.43 & & & \\
\hline & $4^{\text {th }}(\mathrm{Pt}-\mathrm{O})$ & 8 & 3.65 & & & \\
\hline \multirow{4}{*}{$\begin{array}{l}\mathrm{Pd} \mathrm{PtTiO}_{2} / \\
\mathrm{H}-\mathrm{ZSM}-5 \text { (23) }\end{array}$} & $1^{\text {st }}(\mathrm{Pt}-\mathrm{O})$ & 3.5 & 2.02 & 0.0018 & & \\
\hline & $2^{\text {nd }}(\mathrm{Pt}-\mathrm{Pt})$ & 1.2 & 3.00 & 0.0063 & & 0.1 \\
\hline & $3^{\text {rd }}(\mathrm{Pt}-\mathrm{Pt})$ & 1.0 & 3.47 & $0.006^{b}$ & 12.8 & 0.01 \\
\hline & $4^{\text {th }}(\mathrm{Pt}-\mathrm{O})$ & 5.4 & 3.63 & $0.003^{b}$ & & \\
\hline
\end{tabular}

Data from crystallography. ${ }^{\text {bfixed }}$ 
ESI 6

Table S3. Position of the Pd and Pt peaks in eV in XPS analysis

\begin{tabular}{|c|c|c|c|c|}
\hline Sample & $P d 3 d_{5 / 2}$ & $\mathrm{Pd}_{3} \mathrm{~d}_{3 / 2}$ & Pt $4 f_{5 / 2}$ & $\mathrm{Pt} 4 \mathrm{f}_{7 / 2}$ \\
\hline $\mathrm{Pd}, \mathrm{Pt}, \mathrm{TiO}_{2} / \mathrm{H}-\mathrm{ZSM}-5$ (23) & 337.18 & 342.58 & 75.58 & 72.18 \\
\hline $\mathrm{Pd}, \mathrm{Pt}, \mathrm{TiO}_{2} / \mathrm{H}-\mathrm{ZSM}-5$ (50) & 337.08 & 342.28 & 75.48 & 72.08 \\
\hline $\mathrm{Pd}, \mathrm{Pt}, \mathrm{TiO}_{2} / \mathrm{H}-\mathrm{ZSM}-5(80)$ & 336.68 & 342.18 & 75.18 & 71.88 \\
\hline
\end{tabular}




\section{ESI 7}

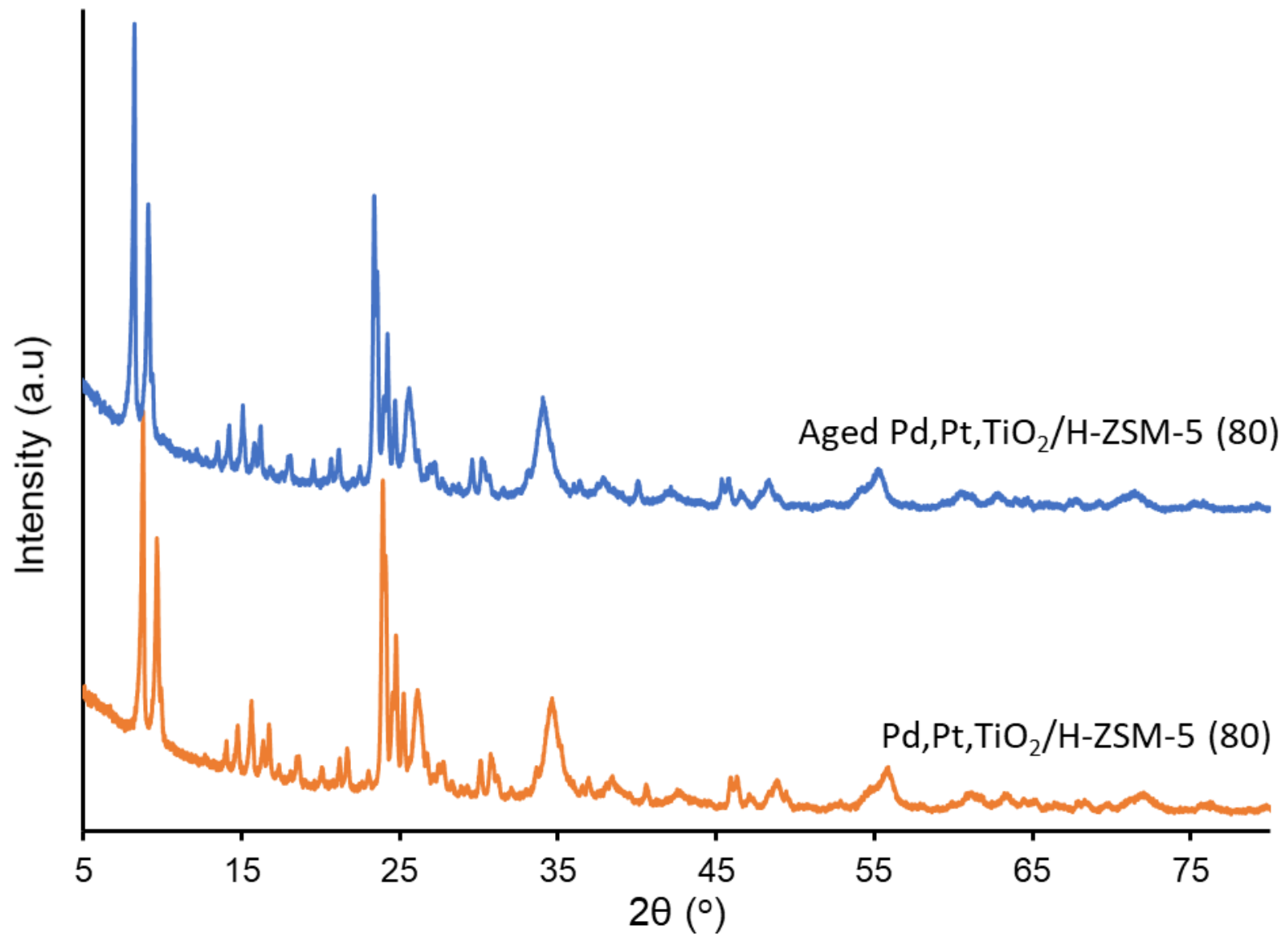

Figure S9. XRD diffractograms of $\mathrm{Pd}, \mathrm{Pt}, \mathrm{TiO}_{2} / \mathrm{H}-\mathrm{ZSM}-5(80)$ and the same material after $50 \mathrm{~h}$ time on stream 


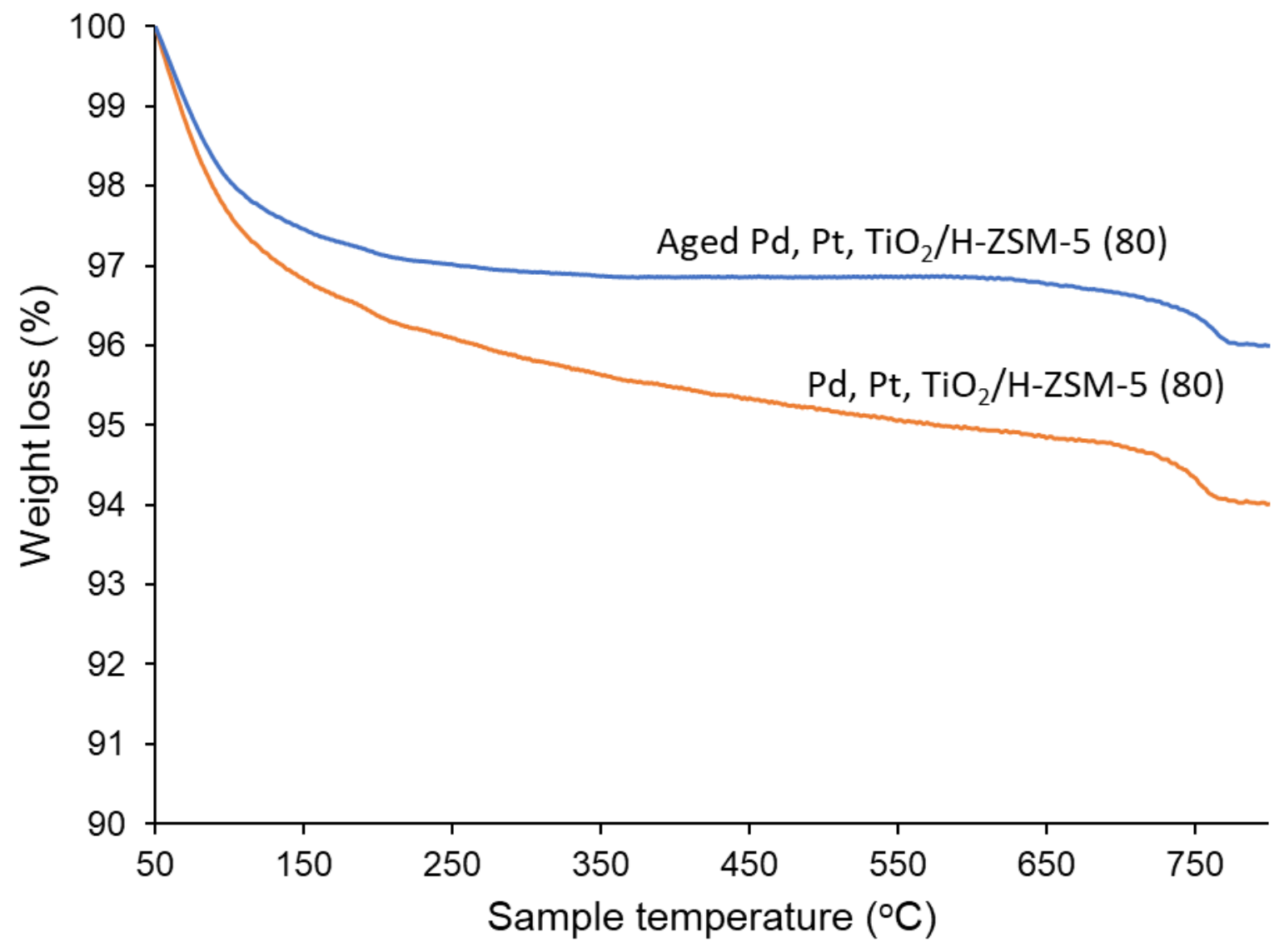

Figure S10. TGA analyses in $\mathrm{O}_{2}$ 

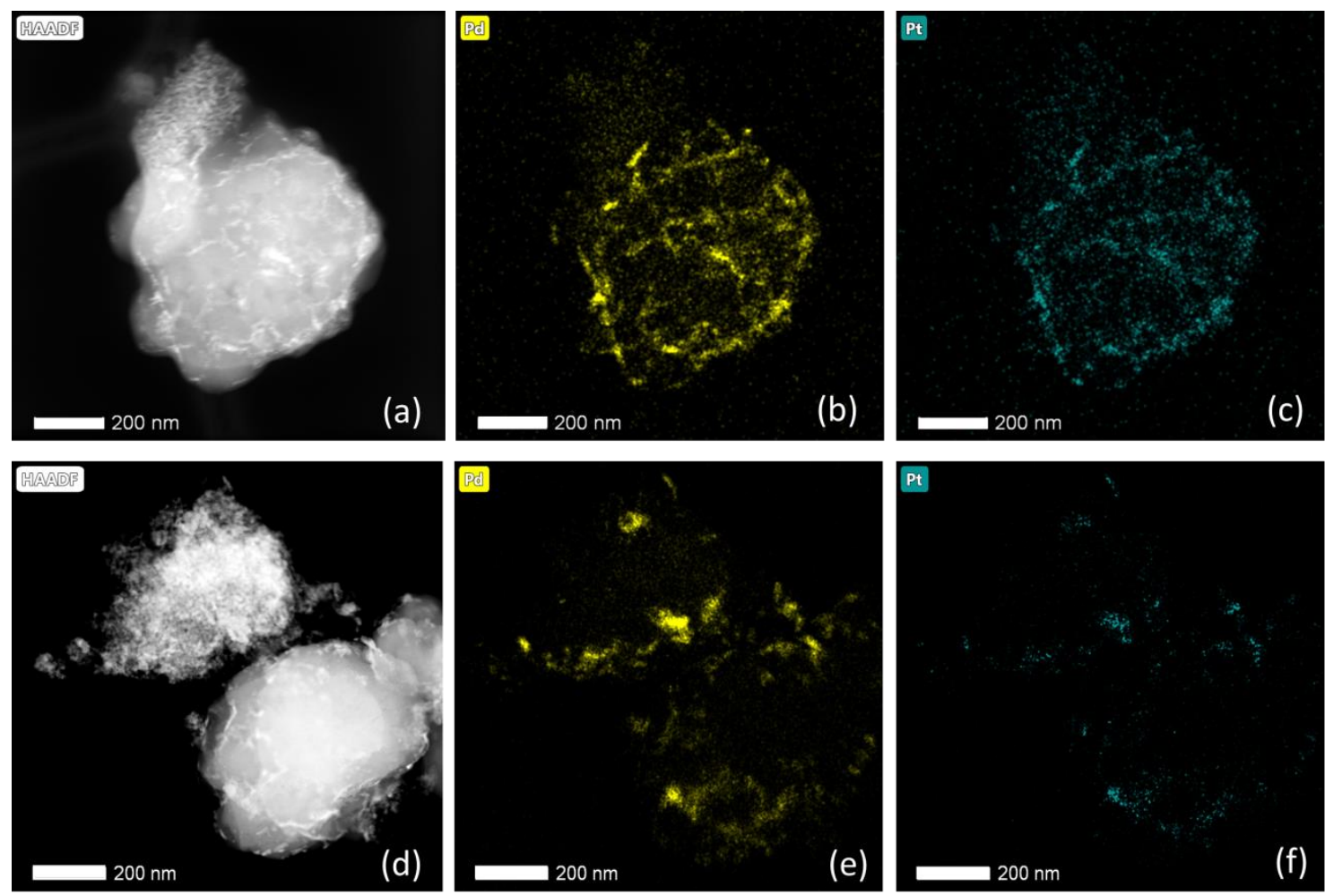

Figure S11. HAADF-STEM images and EDS Pd (yellow), Pt (turquoise) element mapping of (a-c) the original and (d-f) the aged $\mathrm{Pd}, \mathrm{Pt}, \mathrm{TiO}_{2} / \mathrm{H}-\mathrm{ZSM}-5$ (80). 


\section{ESI 8}

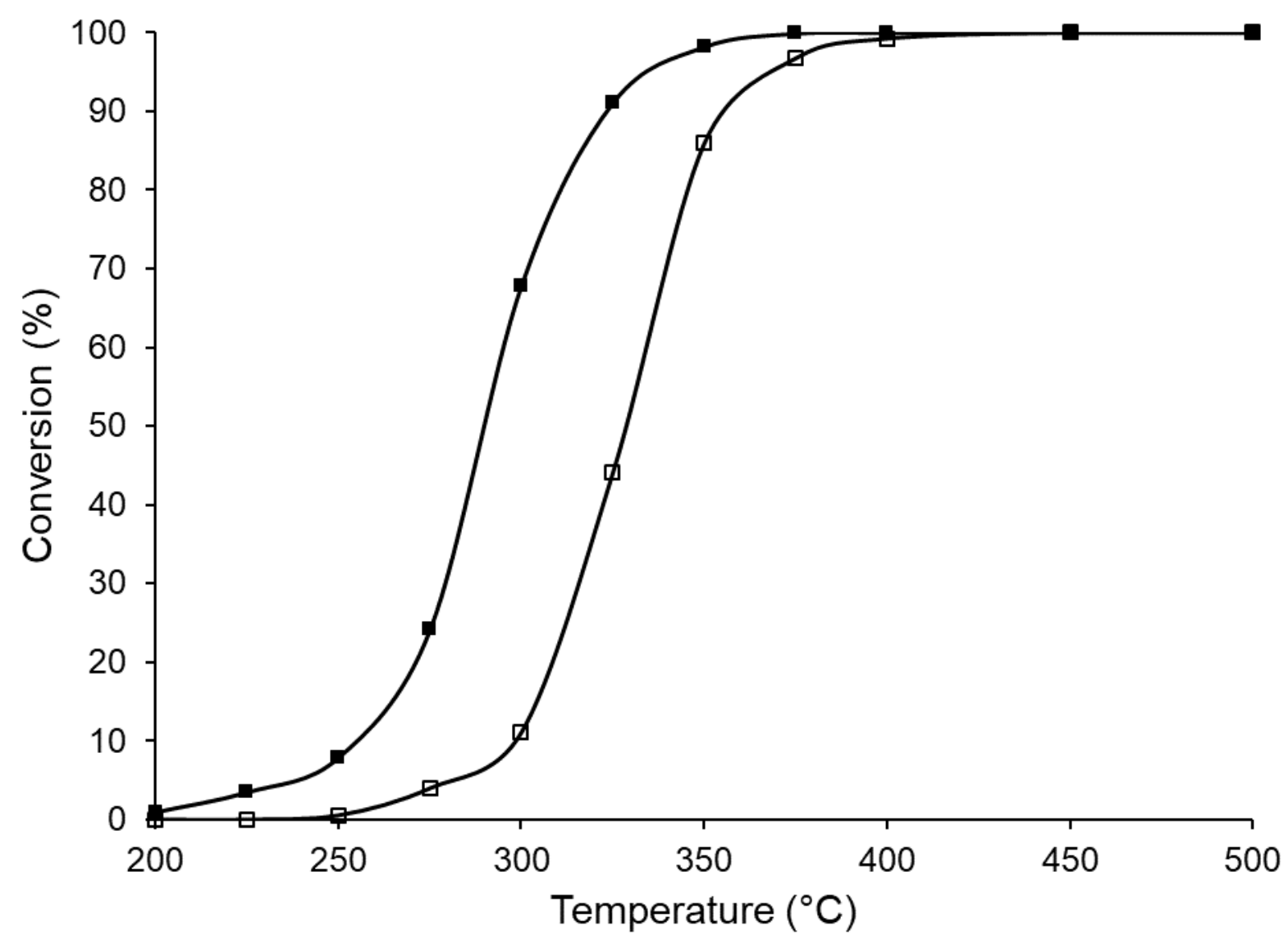

Figure S12. Catalytic activity profiles for methane oxidation under dry conditions (closed symbols) and in the presence of $9 \mathrm{~mL} \mathrm{~min}{ }^{-1}$ water (open symbols) for $\mathrm{Pd}, \mathrm{Pt}, \mathrm{TiO}_{2} / \mathrm{H}-\mathrm{ZSM}-5$ (80). Nominal composition: $5 \mathrm{wt} . \% \mathrm{Pd}, 2 \mathrm{wt} . \% \mathrm{Pt}, 17.5 \mathrm{wt} . \% \mathrm{TiO}_{2}$ on 75.5 wt.\% zeolite. 


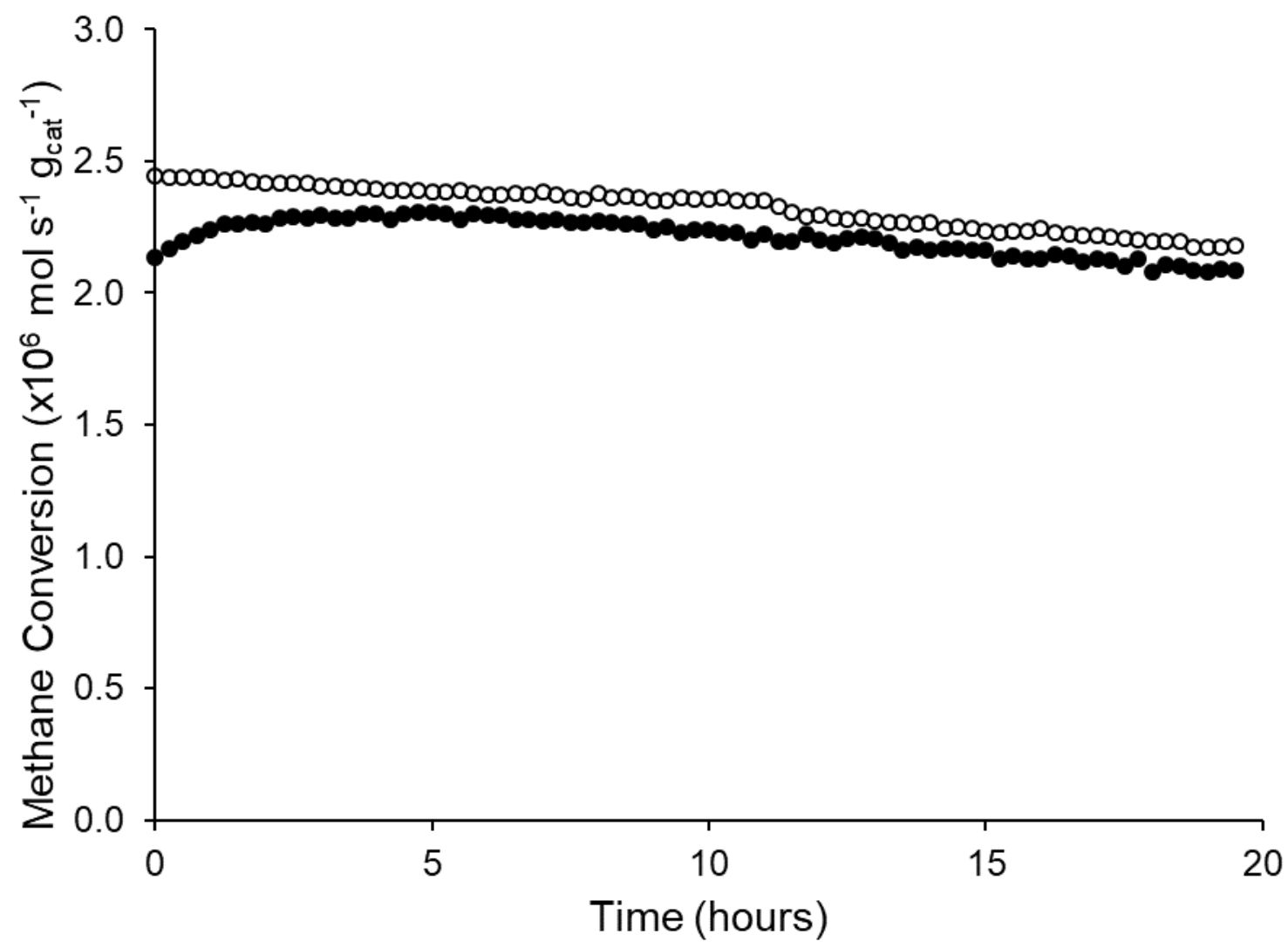

Figure S13. Comparison of the stability of $\mathrm{Pd}, \mathrm{Pt}, \mathrm{TiO}_{2} / \mathrm{ZSM}-5$ (80) under dry conditions at $300{ }^{\circ} \mathrm{C}$ (closed symbols) and in the presence of $9 \mathrm{~mL} \mathrm{~min}^{-1}$ water at $350{ }^{\circ} \mathrm{C}$ (open symbols). 


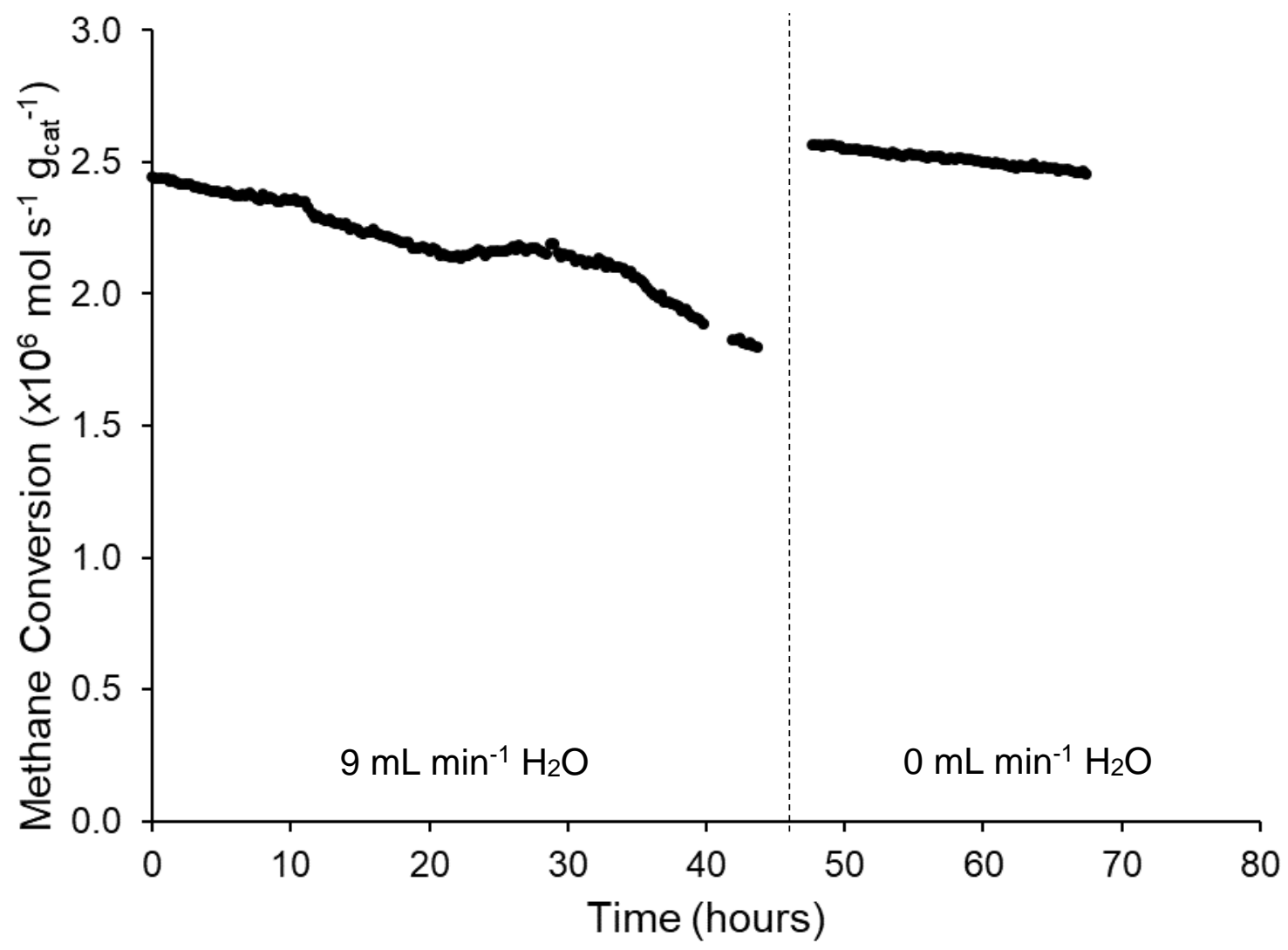

Figure S14. Stability of catalyst Pd,Pt, $\mathrm{TiO}_{2} / \mathrm{H}-\mathrm{ZSM}-5(80)$ with $9 \mathrm{~mL} \mathrm{~min}{ }^{-1}$ water in the feed and when water is removed at $350{ }^{\circ} \mathrm{C}$. Feed composition: $0.9 \mathrm{~mL} \mathrm{~min}{ }^{-1} \mathrm{CH}_{4}$, $18 \mathrm{~mL} \mathrm{~min}^{-1} \mathrm{O}_{2}, 9 \mathrm{~mL} \mathrm{~min}{ }^{-1} \mathrm{Ne}$ and either 9 or $0 \mathrm{~mL} \mathrm{~min}^{-1} \mathrm{H}_{2} \mathrm{O}$ with $152.1 \mathrm{~mL} \mathrm{~min}^{-1} \mathrm{Ar}$. 
References

[1] J.S. S. Lowell, M. A. Thomas, and M. Thommes, Characterization of Porous Solids and Powders: Surface Area, Porosity, and Density, Springer 2004.

[2] R. Haul, S. J. Gregg, K. S. W. Sing: Adsorption, Surface Area and Porosity. 2. Auflage, Academic Press, London 1982. 303 Seiten, Preis: \$ 49.50, Berichte der Bunsengesellschaft für physikalische Chemie, 86 (1982) 957-957.

[3] J. Rouquerol, P. Llewellyn, F. Rouquerol, Is the BET equation applicable to microporous adsorbents?, in: P.L. Llewellyn, F. Rodriquez-Reinoso, J. Rouqerol, N. Seaton (Eds.) Studies in Surface Science and Catalysis, Elsevier 2007, 49-56.

[4] A. Ali, W. Alvarez, C.J. Loughran, D.E. Resasco, State of Pd on H-ZSM-5 and other acidic supports during the selective reduction of $\mathrm{NO}$ by $\mathrm{CH}_{4}$ studied by EXAFS/XANES, Applied Catalysis B: Environmental, 14 (1997) 13-22. 